\title{
TRPV4 and AQP4 Channels Synergistically Regulate Cell Volume and Calcium Homeostasis in Retinal Müller Glia
}

\author{
Andrew 0. Jo, ${ }^{1 \star}{ }^{\circ}$ Daniel A. Ryskamp, ${ }^{1,2 \star}$ Tam T.T. Phuong, ${ }^{1}$ Alan S. Verkman, ${ }^{4}$ Oleg Yarishkin, ${ }^{1}$ Nanna MacAulay, ${ }^{5}$ \\ and $\odot$ David Križaj ${ }^{1,2,3}$ \\ ${ }^{1}$ Department of Ophthalmology and Visual Sciences, Moran Eye Institute, ${ }^{2}$ Interdepartmental Program in Neuroscience, and ${ }^{3}$ Department of Neurobiology \\ and Anatomy, University of Utah School of Medicine, Salt Lake City, Utah 84132, ${ }^{4}$ Department of Medicine, University of California San Francisco, San \\ Francisco, California 94143, and ${ }^{5}$ Department of Cellular and Molecular Medicine, University of Copenhagen, 2200 Copenhagen, Denmark
}

Brain edema formation occurs after dysfunctional control of extracellular volume partly through impaired astrocytic ion and water transport. Here, we show that such processes might involve synergistic cooperation between the glial water channel aquaporin 4 (AQP4) and the transient receptor potential isoform 4 (TRPV4), a polymodal swelling-sensitive cation channel. In mouse retinas, TRPV4 colocalized with AQP4 in the end feet and radial processes of Müller astroglia. Genetic ablation of TRPV4 did not affect the distribution of $\mathrm{AQP} 4$ and vice versa. However, retinas from $\operatorname{Trpv4^{-/-}}$ and $A q \mathrm{p}^{-/-}$mice exhibited suppressed transcription of genes encoding Trpv4, Aqp4, and the Kir4.1 subunit of inwardly rectifying potassium channels. Swelling and $\left[\mathrm{Ca}^{2+}\right]_{\mathrm{i}}$ elevations evoked in Müller cells by hypotonic stimulation were antagonized by the selective TRPV4 antagonist HC-067047 (2-methyl-1-[3-(4-morpholinyl)propyl]-5phenyl- $N$-[3-(trifluoromethyl)phenyl]-1H-pyrrole-3-carboxamide) or Trpv4 ablation. Elimination of Aqp4 suppressed swelling-induced $\left[\mathrm{Ca}^{2+}\right]_{\mathrm{i}}$ elevations but only modestly attenuated the amplitude of $\mathrm{Ca}^{2+}$ signals evoked by the TRPV4 agonist GSK1016790A [(N-((1S)-1-\{[4-((2S)-2-\{[(2,4-dichlorophenyl)sulfonyl]amino\}-3-hydroxypropanoyl)-1-piperazinyl]carbonyl\}-3-methylbutyl)-1-benzothiophene-2-carboxamide]. Glial cells lacking TRPV4 but not AQP4 showed deficits in hypotonic swelling and regulatory volume decrease. Functional synergy between TRPV4 and AQP4 during cell swelling was confirmed in the heterologously expressing Xenopus oocyte model. Importantly, when the swelling rate was osmotically matched for AQP4-positive and AQP4-negative oocytes, TRPV4 activation became independent of $\mathrm{AQP} 4$. We conclude that $\mathrm{AQP} 4$-mediated water fluxes promote the activation of the swelling sensor, whereas $\mathrm{Ca}^{2+}$ entry through TRPV4 channels reciprocally modulates volume regulation, swelling, and Aqp4 gene expression. Therefore, TRPV4-AQP4 interactions constitute a molecular system that fine-tunes astroglial volume regulation by integrating osmosensing, calcium signaling, and water transport and, when overactivated, triggers pathological swelling.

Key words: aquaporin 4; Muller cell; osmoregulation; retina; swelling; TRPV4

\section{Significance Statement}

We characterize the physiological features of interactions between the astroglial swelling sensor transient receptor potential isoform 4 (TRPV4) and the aquaporin 4 (AQP4) water channel in retinal Müller cells. Our data reveal an elegant and complex set of mechanisms involving reciprocal interactions at the level of glial gene expression, calcium homeostasis, swelling, and volume regulation. Specifically, water influx through AQP4 drives calcium influx via TRPV4 in the glial end foot, which regulates expression of Aqp4 and Kir4.1 genes and facilitates the time course and amplitude of hypotonicity-induced swelling and regulatory volume decrease. We confirm the crucial facets of the signaling mechanism in heterologously expressing oocytes. These results identify the molecular mechanism that contributes to dynamic regulation of glial volume but also provide new insights into the pathophysiology of glial reactivity and edema formation.

\section{Introduction}

Osmolality in the brain is an important physiological parameter that is under stringent homeostatic control. Activity-dependent

Received May 22, 2015; revised Aug. 26, 2015; accepted Aug. 27, 2015.

Author contributions: N.M. and D.K. designed research; A.O.J., D.A.R., T.T.T.P., O.Y., N.M., and D.K. performed research; A.S.V. contributed unpublished reagents/analytic tools; A.O.J., D.A.R., T.T.T.P., O.Y., N.M., and D.K. analyzed data; D.A.R., N.M., and D.K. wrote the paper. fluxes of osmolytes and the volume of the extracellular space (ECS) are disproportionately regulated by astrocytes, which take up neuroactive substances (glutamate, $\mathrm{K}^{+}$, protons) and redis- 
tribute water among neuronal, glial, vascular, and ECS compartments. Osmotic gradients, caused by even relatively low levels of neuronal activity, cause sizeable increases in astrocyte volume as a result of influx of $\mathrm{K}^{+}$and water (Risher et al., 2009; MacAulay and Zeuthen, 2010; Florence et al., 2012). Pathological swelling of astrocytes, caused by augmented rates of water flow into and out of the brain, occurs in many CNS diseases (Manley et al., 2000; Papadopoulos and Verkman, 2013). Therefore, investigations into the molecular mechanisms through which astrocytes sense osmotic imbalance and regulate their water and ionic homeostasis represent an important facet of translational neuroscience. However, it is unclear whether glial swelling is sensed by a single type of sensor molecule or whether it involves complex mechanisms composed of multiple components (Pasantes-Morales et al., 2006).

Swelling in primary, cultured astrocytes and astrocytes in vivo is associated with dynamic changes in $\left[\mathrm{Ca}^{2+}\right]_{\mathrm{i}}$ that can have multiple effects on cell physiology, including stimulation of $\mathrm{Ca}^{2+}$ dependent ion channels, glycogen synthesis, release of osmolytes, gliotransmitters, and arachidonic acid. Swelling in astrocytes can also lead to activation of regulatory volume decrease (RVD; an adaptive decrease in cell volume in the continued presence of hypotonicity; Kimelberg et al., 1992; Schliess et al., 1996; Fischer et al., 1997; Hoffmann et al., 2009). In addition, $\mathrm{Ca}^{2+}$ signals were associated with reactive gliosis, a graded progression of molecular, cellular, and functional changes in astrocytes that represents a hallmark of nearly every brain pathology (Huang et al., 2011; Kanemaru et al., 2013). Elimination of aquaporin 4 (AQP4) channels abolished hypotonically induced swelling-mediated $\mathrm{Ca}^{2+}$ signals, altered activity-dependent changes in ECS volume, and compromised glial RVD (Pannicke et al., 2010; Benfenati et al., 2011; Haj-Yasein et al., 2015). The impermeability of AQP4 to ions suggests that other channels must subserve swelling-induced $\mathrm{Ca}^{2+}$ entry. A strong candidate is transient receptor potential isoform 4 (TRPV4), a polymodal nonselective cation channel that was proposed to bind and/or functionally interact with multiple AQP isoforms (Liu et al., 2006; Benfenati et al., 2011; Galizia et al., 2012). The mechanism by which AQP4 might activate TRPV4 is unclear and the functional significance of AQP-TRPV4 interactions for astrocyte swelling, volume regulation, and intracellular signaling remains to be determined. Because TRPV4 expression is confined to a subset $(\sim 30 \%)$ of cortical astrocytes (Shibasaki et al., 2014), we studied the effect of TRPV4-AQP4 interactions in Müller glia, which show close to 100\% penetrance for both channels (Nagelhus et al., 1998; Ryskamp et al., 2014). Taking advantage of $\operatorname{Tr} p v 4^{-/-}$and $A q p 4^{-/-}$animal models, we demonstrate that TRPV4 and AQP4 cooperatively participate in swelling-induced $\mathrm{Ca}^{2+}$ signaling and retinal glial cell volume regulation under hypotonic challenges. We confirmed the functional significance of AQP4-TRPV4 interactions in the Xenopus laevis expression system, leading us to conclude that the two structurally highly dissimilar channels form a functional symbiotic unit that mediates swelling-induced signaling and volume

the University of Utah Undergraduate Research Opportunity Program (A.O.J.), Willard L. and Ruth P. Eccles Foundation, and unrestricted support from Research to Prevent Blindness (to Moran Eye Institute). We thank Dr. Wolfgang Liedtke (Duke University, Durham, NC) for Trpv $4^{-/-}$mice and Alomone Labs for the anti-Kir4.1 antibody sample. *A.O.J. and D.A.R. contributed equally to this work.

Correspondence should be addressed to either of the following: David Križaj, 65 North Mario Capecchi Drive, Building 523, Room S4140 JMEC, Salt Lake City, UT 84132, E-mail: david.krizaj@hsc.utah.edu; or Daniel Ryskamp, 5323 Harry Hines Boulevard, Pickens Biomedical Building, Room ND12.200A, Dallas, TX 75390, E-mail: daniel.ryskamp@utsouthwestern.edu.

DOI:10.1523/JNEUROSCI.1987-15.2015

Copyright $\odot 2015$ the authors $\quad 0270-6474 / 15 / 3513526-13 \$ 15.00 / 0$ regulation in the retina. Part of this paper have been published previously in abstract form (Križaj et al., 2013).

\section{Materials and Methods}

Animals. For mice, experiments were conducted in accordance with the National Institutes of Health Guide for the Care and Use of Laboratory Animals, the Association for Research in Vision and Ophthalmology Statement for the Use of Animals in Ophthalmic and Vision Research, and the Institutional Animal Care and Use Committees at the University of Utah. C57BL/6J mice, Trpv4 $4^{-/-}$mice with excised exon 12-encoding transmembrane pore domains 5 and 6 (Liedtke and Friedman, 2003), and $A q p 4^{-1-}$ mice with part of exon 1 replaced with a selection cassette causing transcript truncation (Ma et al., 1997) were maintained in a pathogen-free facility with a $12 \mathrm{~h}$ light/dark cycle and ad libitum access to food and water. Data were gathered from male and female mice, but no gender differences were noted. For Xenopus laevis, experiments complied with the European Community guidelines for the use of experimental animals and were approved by the Danish National Committee for Animal Studies.

Reagents. The TRPV4 antagonist HC-067047 (2-methyl-1-[3(4-morpholinyl)propyl]-5-phenyl- $N$-[3-(trifluoromethyl)phenyl]-1 Hpyrrole-3-carboxamide) (HC-06) was purchased from Calbiochem or Sigma. Arachidonic acid and phospholipase A2 (PLA2) antagonists were purchased from Cayman Chemical or Sigma. All other salts and reagents were purchased from Sigma. GSK1016790A [(N- ( $1 S)-1-\{[4-$ ((2S)-2-\{[(2,4-dichlorophenyl)sulfonyl $]$ amino $\}$-3-hydroxypropanoyl)1-piperazinyl] carbonyl\}-3-methylbutyl)-1-benzothiophene-2-carboxa mide] (GSK101; 1-10 mM) and HC-06 (4 mm) stock in DMSO were diluted 1:1000 in extracellular saline just before use and placed into reservoirs connected to gravity-fed perfusion systems (Warner Instruments).

Semiquantitative real-time PCR. Retinas were collected from two to four mice per group [wild type (WT), $\operatorname{Tr} p v 4^{-1-}$, and Aqp $4^{-1-}$ cohorts]. Retinal RNA was isolated with the TRI Reagent (Sigma), and total RNA concentrations ( $5 \mu \mathrm{g}$ ) were converted to cDNA using the SuperScript III First-Strand Synthesis kit (Invitrogen). RT-PCR was performed using the Cyber Green PCR master mix (Applied Biosystems) and was run on the CFX Connect Real-Time PCR System (Bio-Rad) following the protocols of the manufacturer (Takara; $95^{\circ} \mathrm{C}$ for $15 \mathrm{~s}, 95^{\circ} \mathrm{C}$ for $5 \mathrm{~s}, 60^{\circ} \mathrm{C}$ for $30 \mathrm{~s}, 40$ cycles). After amplification, the ratio of gene-of-interest mRNA to the housekeeping gene $\alpha$-tubulin was calculated for each sample. Four to eight independent biological replicates (retinas) were used. The primers are listed in Table 1.

Immunofluorescence. Enucleated eyes were punctured and fixed in $4 \%$ paraformaldehyde in PBS for $10 \mathrm{~min}$. Eyes were hemisected, and the eyecup was fixed for another 50-60 min. After three washes for $10 \mathrm{~min}$ with PBS, eyecups were cryoprotected by incubation in $15 \%$ sucrose for $45 \mathrm{~min}$ at room temperature and in $30 \%$ sucrose overnight at $4^{\circ} \mathrm{C}$ (Witkovsky et al., 2008; Ryskamp et al., 2011). Eyecups were transferred to OCT (Ted Pella), frozen at $-80^{\circ} \mathrm{C}$, sliced with a cryostat $(16 \mu \mathrm{m} \mathrm{sec}-$ tions), and mounted onto Superfrost Plus slides. Slices were dried for $1 \mathrm{~h}$ at room temperature or overnight at $4^{\circ} \mathrm{C}$ before processing for immunohistochemistry or storage at $-80^{\circ} \mathrm{C}$. After washing with PBS, slices were blocked for $30 \mathrm{~min}$ in blocking buffer ( $10 \mathrm{ml}$ of PBS, $30 \mu \mathrm{l}$ of Triton $\mathrm{X}-100,100 \mathrm{mg}$ of BSA, and $200 \mu \mathrm{l}$ of $5 \% \mathrm{w} / \mathrm{v} \mathrm{Na}$ azide solution). Primary antibodies were diluted in PBS and applied overnight at $4^{\circ} \mathrm{C}$. After rinsing, slices were incubated with secondary antibodies diluted to 1:1000 in PBS $1 \mathrm{~h}$ at room temperature. Unbound antibodies were rinsed away, and conjugated fluorophores were protected with Fluoromount-G (Southern Biotech) before mounting coverslips and confocal imaging. Primary antibodies included the following: rabbit anti-TRPV4 (1:1001:1000; Lifespan Biosciences), rabbit anti-Kir4.1 (1:500; catalog \#APC035; Alomone), guinea pig anti-Kir4.1 (1:200; catalog \#AGP-012; Alomone), rabbit anti-glial fibrillary acidic protein (GFAP; 1:500; catalog \#Z0334; Dako), mouse anti-glutamine synthetase (GS; 1:1000-1:2000; catalog \#610517; BD Biosciences), and mouse anti-AQP4 (1:1000; catalog \#SC-20812; Santa Cruz Biotechnology). Goat anti-mouse, goat antirabbit, and goat anti-guinea pig IgG (heavy and light chain) secondary antibodies were conjugated to fluorophores (Alexa Fluor 488 or Alexa Fluor 594; Life Technologies). The primary antibodies did not label 
Table 1. Primers used in the study

\begin{tabular}{|c|c|c|}
\hline Primer & Sequence $\left(5^{\prime}\right.$ to $\left.3^{\prime}\right)$ & GenBank accession numbers \\
\hline mAqp4 sense & AGCAATTGGATTTTCCGTTG & NM_009700 \\
\hline mAqp4 antisense & TGAGCTCCACATCAGGACAG & \\
\hline mKir4.1 sense & GCCCTAGGACTGATGAGCTG & NM_001039484 \\
\hline mKir4.1 antisense & AACAGTAGGGAGCAGCCAGA & \\
\hline mTrpv4 sense & TCCTGAGGCCGAGAAGTACA & NM_022017.3 \\
\hline mTrpv4 antisense & TCCCCCTCAAACAGATTGGC & \\
\hline mTuba1a sense & AAGCAGCAACCATGCGTGA & NM_011653.2 \\
\hline mTuba1a antisense & сCTCCCCCAATGGTCTTGTC & \\
\hline mGlulsense & TTGGTCTCTGCAGGTTTCCG & NM_008131.4 \\
\hline mGlul antisense & TTGGTCTCTGCAGGTTTCCG & \\
\hline mActb sense & CCACCATGTACCCAGGCATT & NM_007393.4 \\
\hline$m A c t b$ antisense & AGGGTGTAAAACGCAGCTCA & \\
\hline mGapdh sense & GGTTGTCTCCTGCGACTTCA & NM_001289726.1 \\
\hline mGapdh antisense & TAGGGCCTCTCTTGCTCAGT & \\
\hline 185 rRNA sense & GCAATTATTCCCCATGAACG & NR_003278.3 \\
\hline 185 rRNA antisense & GGCCTCACTAAACCATCCAA & \\
\hline
\end{tabular}

knock-out (KO) tissues (Da and Verkman, 2004; Ryskamp et al., 2011). Secondary antibodies did not label retinal tissue when primary antibodies were omitted. Immunostaining was imaged with confocal microscopes (Zeiss LSM 510 or Olympus FV1200) using argon (488 nm) and helium/neon (543 nm) lasers, suitable emission filters, and $40 \times / 1.2 \mathrm{nu}-$ merical aperture (NA) oil-immersion or $40 \times / 0.9$ NA water-immersion objectives.

Acute dissociation of Müller cells. After the animals were killed, mouse eyes were enucleated, and retinas were isolated by dissection in ice-cold Leibovitz 15 (L-15) medium (Life Technologies) containing $11 \mathrm{mg} / \mathrm{ml}$ L-15 powder, $20 \mathrm{~mm}$ D-glucose, $10 \mathrm{~mm}$ Na-HEPES, $2 \mathrm{~mm}$ Na-pyruvate, $0.3 \mathrm{~mm} \mathrm{Na}$-ascorbate, and $1 \mathrm{~mm}$ glutathione. Retinas were incubated at room temperature in $\mathrm{L}-15$ medium containing papain $(7 \mathrm{U} / \mathrm{ml}$; Worthington) to digest the extracellular matrix. Retinas were rinsed with cold $\mathrm{L}-15$ medium and diced into $\sim 500 \mu \mathrm{m}$ pieces. One to two pieces of retina were dissociated mechanically by trituration and plated on coverslips pretreated with concanavalin A $(1 \mathrm{mg} / \mathrm{ml})$. Plated cells were loaded with the ratiometric $\mathrm{Ca}^{2+}$ indicator fura-5F AM for 30-40 min and were washed for 10-20 min in dye-free $\mathrm{L}-15$ medium. $\mathrm{Ca}^{2+}$ homeostasis and stimulus responsiveness is maintained for several hours under these experimental conditions (Ryskamp et al., 2014). Müller cells were identified by their distinctive morphology and prominent $\mathrm{Ca}^{2+}$ signals during TRPV4 activation. Cellular identity was confirmed in a subset of experiments by post-imaging immunocytochemistry (mouse anti-GS) as in the study by Ryskamp et al. (2014).

Superfusion of Müller cells and cell swelling assays. Volume regulation in dissociated Müller glia was investigated following published protocols (Ryskamp et al., 2011, 2014). Briefly, saline solutions were delivered through a gravity-fed eight-reservoir system (Warner Instruments) that converged toward a manifold tube inserted into the experimental chamber. The control saline contained the following (in $\mathrm{mm}$ ): $133 \mathrm{NaCl}, 2.5$ $\mathrm{KCl}, 1.5 \mathrm{NaH}_{2} \mathrm{PO}_{4}, 1.5 \mathrm{MgCl}_{2}\left(6 \mathrm{H}_{2} 0\right), 2 \mathrm{CaCl}_{2}, 10$ glucose, 10 HEPES hemisodium salt, 1 pyruvic acid, 1 lactic acid, 0.5 L-glutamine, 0.5 glutathione, and 0.3 Na-ascorbate, $\mathrm{pH} 7.4$ (osmolarity at $300 \mathrm{mOsm}$ ). With $\mathrm{NaCl}$ kept at $57.5 \mathrm{~mm}$, anisosmotic solutions were prepared by addition or removal of mannitol, a procedure that maintains the ionic strength of the extracellular solution. Mannitol may reduce the contribution of volume-activated channels to RVD, whereas the reduction in $\mathrm{NaCl}$ could disinhibit volume-activated chloride channels (Fernández et al., 2013; Minieri et al., 2015). Osmolarity was checked thermometrically using a vapor pressure osmometer (Wescor). Cell volume was measured by calcein fluorescence and by adapting a protocol developed by the Putney laboratory (Chiavaroli et al., 1994). Fluorescence emissions from 340 and $380 \mathrm{~nm}$ stimuli were normalized to baseline fluorescence and algebraically summed $\left(F_{\mathrm{vol}}=F_{340}+F_{380} / x\right.$, where $x=1-3$, a value derived empirically for each preparation to equalize the magnitude of the $\mathrm{Ca}^{2+}$ dependent and opposing changes in $F_{340}$ and $F_{380}$ ). Thus, at the appropriate $x$ value, the intensity of the summed fluorescence was calcium insensitive (i.e., the summed trace showed no response to GSK101 or glutamate). In a subset of experiments using hypotonic stimulation (HTS), cells were coloaded with fura-5F AM and calcein AM (1 $\mu \mathrm{M}$; Invitrogen). Calcein fluorescence was evoked using $490 \mathrm{~nm}$ excitation attenuated as described previously (Ryskamp et al., 2011). The $x-y$ crosssectional area was determined offline using NIS-Elements AR 3.2 or Olympus image analysis software. We confirmed with confocal $z$ stacks over time that swelling occurs uniformly in all directions (Ryskamp et al., 2014), indicating that cell volume is proportional to $\mathrm{V} \mathrm{area}^{3}$. The percentage RVD was calculated as $100 \times$ (peak cell area in hypotonicity cell area at the end of hypotonicity)/(peak cell area in hypotonicity - cell area before hypotonicity).

Calcium imaging. Epifluorescence images were acquired using an inverted Nikon Ti or an upright Nikon E600 FN microscope with $20 \times$ ( 0.75 NA oil-immersion), $40 \times$ ( 1.3 NA oil-immersion and 0.8 NA waterimmersion), and $60 \times$ (1.0 NA water-immersion) objectives. Excitation light from a xenon arc lamp was delivered and filtered using a Lambda DG-4 (Sutter Instruments). Emissions were detected with 14-bit CoolSNAP $\mathrm{HQ}^{2}$ cameras and analyzed using NIS-Elements AR 3.2 and MS Excel. $\left[\mathrm{Ca}^{2+}\right]_{\mathrm{i}}$ was detected using the ratiometric fluorescent dyes fura-2 $\left(K_{\mathrm{d}}\right.$ at room temperature $\left.=225 \mathrm{nM}\right)$ and fura- $5 \mathrm{~F}\left(K_{\mathrm{d}}\right.$ at room temperature $=400 \mathrm{~nm}$; Invitrogen Handbook) as described previously (Molnar et al., 2012; Ryskamp et al., 2014). Although cells were loaded with 5-10 $\mu \mathrm{M}$ of the AM dyes, trapping by de-esterification was assumed to accumulate them to $\sim 100 \mu \mathrm{M}$ (Križaj and Copenhagen, 1998). $\Delta R / R$ (peak $F_{340} / F_{380}$ ratio - baseline/baseline) was used to quantify the amplitude of $\mathrm{Ca}^{2+}$ signals. In a subset of experiments using extreme HTS $(\leq 30 \%$ tonicity), the duration of $380 \mathrm{~nm}$ excitation was increased to decrease signal noise. Results represent averages of Müller cell responses from at least three animals.

Electrophysiology in Müller glia. Retinal pieces were incubated in L-15 medium, and cells were dissociated, plated, and identified as described previously (Szikra et al., 2009; Ryskamp et al., 2014). The extracellular solution contained the following (in $\mathrm{mM}$ ): $51 \mathrm{NaCl}, 0.6 \mathrm{Na}_{2} \mathrm{HPO}_{4}, 0.75$ $\mathrm{MgCl}_{2}, 0.5$ sodium pyruvate, 5 lactic acid, 5 HEPES hemisodium salt, 0.5 glutathione, 0.3 sodium L-ascorbate, $10 \mathrm{D}$-glucose, 0.5 L-glutamine, 2 $\mathrm{CaCl}_{2}$, and 135 mannitol, $\mathrm{pH}$ 7.3. The hypotonic saline had the same composition, without mannitol. Experiments were performed at room temperature $\left(20-22^{\circ} \mathrm{C}\right)$. Solution exchange was achieved through rapid switching of solenoid valves regulating gravity-driven flow through a tubing manifold placed $\sim 5 \mathrm{~cm}$ from the perfusion chamber.

The recording pipettes were pulled using a P-2000 horizontal puller (Sutter Instruments) from borosilicate glass $(1.5 \mathrm{~mm}$ outer diameter, $0.84 \mathrm{~mm}$ inner diameter) to obtain tips with resistance between 8 and 10 $\mathrm{M} \Omega$. We patched Müller end feet, recognized as semicircular protuberances at the end of the proximal stalk. Membrane currents were acquired after application of ramp pulses assessing from -100 to $100 \mathrm{mV}$ for $1 \mathrm{~s}$ (applied at $0.2 \mathrm{~Hz}$ ) using pClamp 10.5 acquisition software (Molecular Devices) and a Digidata 1422 interface (Molecular Devices). Data were sampled at $10 \mathrm{kHz}$ and filtered at $5 \mathrm{kHz}$ with an eight-pole Bessel filter and analyzed using Clampfit 10.5 (Molecular Devices) and Origin Pro8 software. The time dependence of HTS-induced currents was quantified as duration of HTS-induced whole-cell current changes from $5 \%$ of the maximum response to the maximum response.

Heterologous expression in Xenopus oocytes. Xenopus laevis frogs were obtained from Nasco or the National Center for Scientific Research (France). Oocytes were removed surgically from anesthetized frogs and prepared as described previously (Fenton et al., 2010). cDNA encoding rat Trpv4 and Aqp4.M23 in the oocyte expression vector pXOOM (TRPV4 and AQP4.M23) were linearized downstream from the poly(A) segment and in vitro transcribed using T7 mMessage Machine (Ambion). cRNA was extracted with MEGAclear (Ambion) and microinjected into defolliculated Xenopus laevis oocytes (4 ng of TRPV4 and/or $10 \mathrm{ng}$ of AQP4 RNA/oocyte). Oocytes were kept at $19^{\circ} \mathrm{C}$ in Kulori medium (in mм: $90 \mathrm{NaCl}, 1 \mathrm{KCl}, 1 \mathrm{CaCl}_{2}, 1 \mathrm{MgCl}_{2}$, and 5 HEPES, $\mathrm{pH}$ 7.4) for 3-4 d before experiments. Because of basal activity of TRPV4 and associated cell lysis resulting from the toxicity of overexpressed channels, the oocytes were kept in $1 \mu \mathrm{M}$ Ruthenium Red (Sigma) but rinsed before experiments (Loukin et al. 2010). 


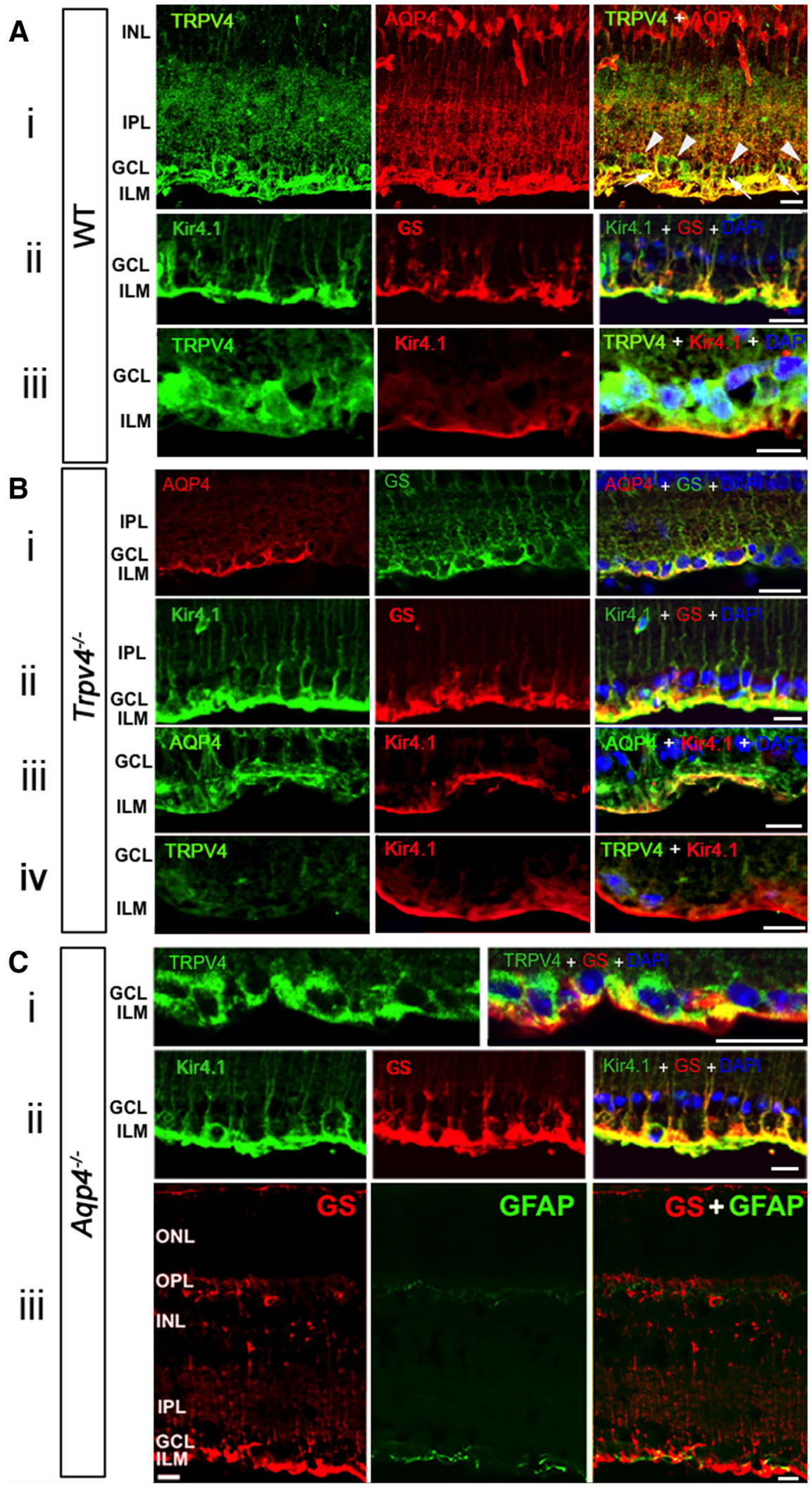

Figure 1. TRPV4 and AQP4 colocalize in the mouse inner retina, yet TRPV4 and AQP4 trafficking are independent of each other. Ai, Vertical cryosections of WT mouse retinas immunolabeled for TRPV4 (Alexa Fluor 488) and AQP4 (Alexa Fluor 594) show preferential colocalization in Müller end feet and proximal processes entering the IPL (arrows). RGC somata are TRPV4 immunopositive and do not express AQP4 (arrowheads). Aii, Aiii, Higher magnification of Müller end feet double labeled for Kir4.1 and GS, and TRPV4 and Kir4.1, respectively. Nuclei labeled with DAPI. GCL, Ganglion cell layer; INL, inner nuclear layer. Scale bars, $20 \mu \mathrm{m}$. Bi-Biii, Trpv4 ${ }^{-1-}$ retina. GS and Kir4.1 signals in KO tissue are indistinguishable from WT controls, whereas AQP4 signals appear to be less pronounced. Biv, Limited nonspecific TRPV4 immunoreactivity in Trpv4 ${ }^{-1-}$ retina costained for Kir4.1. C, Aqp4
Electrophysiology and volume measurements in oocytes. Conventional two-electrode voltage-clamp studies were performed with a Dagan CA-1B High Performance oocyte clamp (Dagan) with Digidata 1322A interface controlled by pClamp 9.2 (Molecular Devices). The oocyte membrane potential was clamped at $-30 \mathrm{mV}$, and the current-voltage $(I-V)$ relationship was determined by stepping the clamp potential to test potentials ranging from +60 to $-140 \mathrm{mV}$ in $20 \mathrm{mV}$ increments $(100 \mathrm{~ms}$ pulses). The experimental setup for measuring water permeability of oocytes has been described in detail previously (Zeuthen et al., 2006). Briefly, the oocyte was placed in a small chamber with a glass bottom and perfused with a control solution (in mM: $40 \mathrm{NaCl}, 2 \mathrm{KCl}, 1$ $\mathrm{CaCl}_{2}, 1 \mathrm{MgCl}_{2}, 125$ mannitol, and 10 HEPES, pH 7.4). Oocyte images were captured continuously from below at a rate of 25 images/s. To induce cell swelling, the oocytes were challenged with a hypotonic solution (composition as in control solution but with removal of 125 or $15 \mathrm{~mm}$ mannitol), and cell swelling was determined as the percentage increase in crosssectional area of the oocyte.

Statistics. Statistical analyses were performed with GraphPad Prism version 6.0. Data were acquired from at least three different retinas and three different batches of oocytes. Means are shown \pm SEM. Unless indicated otherwise, an unpaired $t$ test was used to compare two means, and a one-way or two-way ANOVA along with the Holm-Sidak test was used to compare three or more means. $p>0.05$ is not significant, ${ }^{*} p<0.05,{ }^{* *} p<0.01,{ }^{* * *} p<$ 0.001 , and ${ }^{\star * * *} p<0.0001$.

\section{Results}

TRPV4 colocalizes with AQP4 in Müller glial end feet

Although TRPV4 and AQP channels were implicated in osmotic regulation as sensors and effectors for osmotically induced Müller glial swelling and water flux, respectively (Nagelhus and Ottersen, 2013; Ryskamp et al., 2014), the nature of their combined contribution to cellular osmoregulation is not well defined. Therefore, we tested whether selective ablation of either channel affects the production and localization of its putative partner and investigated their respective contributions to volume regulation and $\mathrm{Ca}^{2+}$ homeostasis. As shown previously (Nagelhus et al., 1998; Da and Verkman, 2004; Goodyear et al.,

retinas. $\mathrm{Ci}$, TRPV4 and GS colocalize in glial end feet at the blood-retina barrier, whereas RGC somata are immunoreactive for TRPV4. Cii, Double labeling for GS and Kir4.1 shows normal targeting to glial processes and end feet. Ciii, GFAP is expressed in astrocyte processes but is absent from GS immunoreactivity in Müller processes and end feet, indicating absence of reactive gliosis. Scale bars, $20 \mu \mathrm{m}$. 


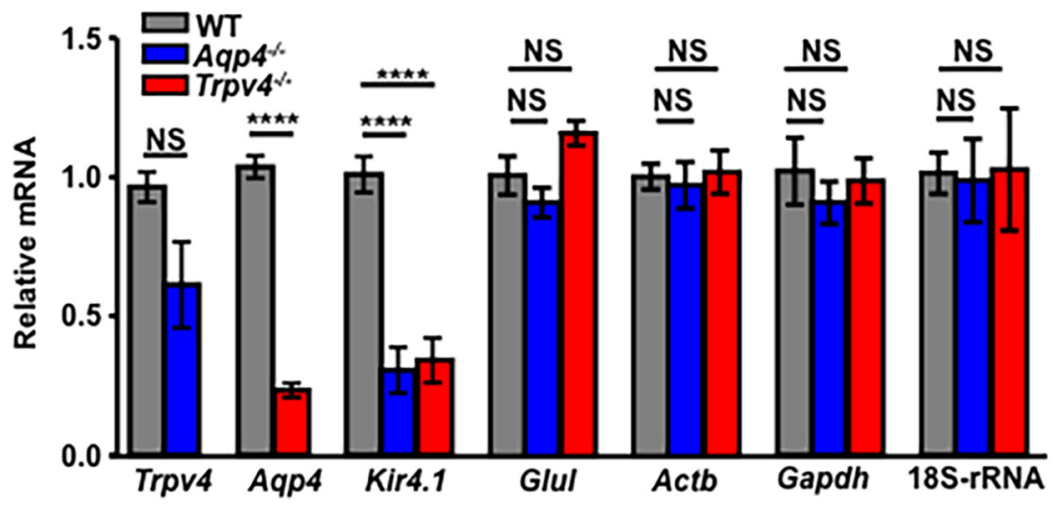

Figure 2. Expression of Trpv4, Aqp4, and Kir4.1 transcripts is effected by genetic elimination of TRPV4 or AQP4. Semiquantita-

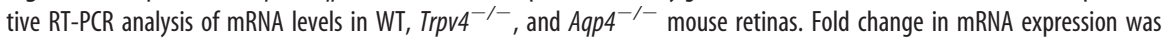
calculated relative to basal after normalization of expression to $\alpha$-tubulin (Tuba1a) mRNA. The relative abundance of Trpv4

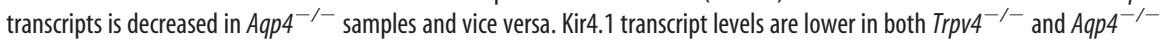
retinas, whereas the abundance of presumed housekeeping genes Glul, Actb, Gapdh, and 185 rRNA (the 185 structural subunit of the small eukaryotic 40 S ribosomal subunit, 18S-rRNA) mRNAs was unaffected by the deletion of Trpv4 or Aqp4.

2009), immunostaining of WT mouse retinas with the AQP4 antibody labeled Müller cell somata within the inner nuclear layer, inner retinal processes, and end feet forming the pericapillary sheath within the inner limiting membrane (ILM; Fig. 1Ai). Likewise, consistent with Müller glial expression, TRPV4 immunoreactivity was observed in glial end feet and transverse processes in the proximal inner plexiform layer (IPL) in which it overlapped with Müller cell markers GS and the inwardly rectifying $\mathrm{K}^{+}$channel (composed of Kir4.1 subunits) that has been suggested to regulate Müller cell resting membrane potential and underlie retinal $\mathrm{K}^{+}$siphoning toward vascular sinks (Newman, 1985; Fig. 1Aii). The extensive colocalization between AQP4 and TRPV4 signals included pronounced overlap within the end foot compartment and radial processes traversing the IPL (Fig. 1Ai, top, arrows), whereas TRPV4-Kir4.1 colocalization was less pronounced, with the latter signal most concentrated in the most proximal portion of the ILM (Fig. 1Aiii). AQP4-immunonegative TRPV4-immunoreactive signals in the inner retina correspond to retinal ganglion cell (RGC) somata (Fig. 1A, arrowheads) and proximal dendrites. The colocalization of TRPV4, AQP4, and Kir4.1 channels in Müller end feet is consistent with a putative synergistic function of these channels in Müller cell volume regulation at the blood-retina barrier.

If AQP4 channels in Müller glia form an obligatory complex with TRPV4, the distribution and/or expression of the osmosensor might be influenced by AQP4 elimination (Benfenati et al., 2011). However, evaluation of Müller glial morphology and TRPV4 immunolocalization in Aqp $4^{-/-}$retinas (Fig. 1Ci) failed to reveal substantial differences from WT retinas (Fig. 1A). Aqp $4^{-/-}$retinas did not show a discernible phenotype in terms of layering, cytoarchitecture, and Kir4.1 immunoreactivity (Fig. 1Cii). To test the possibility that targeting of AQP4/Kir4.1 channels to the plasma membrane might depend on TRPV4 channels, we examined their respective immunoreactivities in $\operatorname{Tr} p v 4^{-/-}$ retinas. $\operatorname{Trp} v 4^{-/-}$retinas were morphologically normal, evincing the typical Kir4.1 localization patterns within Müller cell processes and end feet (Fig. 1B). Further suggestive of normal Müller glial morphological and molecular characteristics in $\mathrm{KO}$ tissue was the typical expression pattern of GS staining in $\operatorname{Trpv} 4^{-/-}$ retinas and $A q p 4^{-1-}$ retinas (Fig. 1 Aii,Bii,Cii/Ciii). Consistent with downregulation of $A q p 4$ mRNA (Fig. 2), the intensity of
AQP4 labeling in Trpv4 $4^{-/-}$retinas appeared to be lower (Fig. $1 \mathrm{Bi}, \mathrm{Biii}$ ) compared with WT tissue (Fig. 1Ai).

Müller cells respond to injury with reactive gliosis, an adaptive response typified by astroglial hypertrophy and cytoskeletal reorganization that can be visualized by upregulation of the gliotic marker GFAP. In the retina, astrocytes on the vitreal surface constitutively express GFAP, whereas Müller glia only express GFAP during the reactive response. We noted previously that ablation of the Trpv4 gene and TRPV4 overactivation in vivo result in mild Müller glial reactivity indicated by de novo GFAP expression (Ryskamp et al., 2014). Here we examined whether the absence of physiological AQP4 functions might evoke a similar gliotic response. Although astrocytes on the vitreal surface were labeled clearly by the GFAP antibody, the marker was absent from the radial processes of Müller glia (Fig. 1Ciii). This absence of overt retinal distress is consistent with the previous report by Pannicke et al. (2010) and implies that AQP4 may have more subtle roles in normal retinal function (Li et al., 2002), whereas AQP4-mediated water fluxes may have more influence under pathophysiological conditions ( $\mathrm{Da}$ and Verkman, 2004).

These results suggest the following: (1) TRPV4 expression is not a prerequisite for proper trafficking or localization of AQP4 and Kir4.1; (2) AQP4 expression is not required for trafficking or localization of TRPV4 and Kir4.1; and (3) unlike loss of TRPV4, which is associated with reactive gliosis (Ryskamp et al., 2014), loss of AQP4 function does not induce Müller glial expression of the gliotic marker GFAP.

\section{Genetic deletion of TRPV4 and AQP4 alters the transcription of Trpv4, Aqp4, and Kir4.1 genes}

Despite independent trafficking of TRPV4 and AQP4 to Müller end feet, the two channels might interact indirectly through their effects on gene expression, calcium homeostasis, cell swelling, and/or volume regulation. We analyzed the expression of $\operatorname{Trp} v 4$ and Aqp4 transcripts in $\mathrm{KO}$ retinas but also tested for expression of Kir4.1 mRNA, because these inwardly rectifying $\mathrm{K}^{+}$channels were suggested to form a complex with AQP4 (Puwarawuttipanit et al., 2006) and TRPV4 (Lanciotti et al., 2012) and are strongly expressed in Müller glial end feet (Fig. 1). Analysis of Aqp4 $4^{-/-}$ retinas $(n=8)$ showed a substantial $(69.48 \pm 8.27 \% ; p<0.0001)$ reduction in the abundance of Kir4.1 transcripts and a nonsignificant $38.71 \pm 15.43 \%$ decrease in Trpv 4 mRNA (Fig. 2). Likewise, Aqp4 and Kir4.1 transcript levels were markedly reduced in $\operatorname{Trp} v 4^{-1-}$ retinas $[76.72 \pm 2.55 \%($ Aqp 4$)$ and $65.85 \pm 8.04 \%$ (Kir4.1); $n=8 ; p<0.0001$; Fig. 2]. Analysis of genes presumably unrelated to TRPV4 and AQP4 function, i.e., GS (Glul), glyceraldehyde-3-phosphate dehydrogenase (Gapdh), $\beta$-actin $(A c t b)$, and the $18 \mathrm{~S}$ ribosomal subunit genes, showed no significant changes in transcription upon deletion of $A q p 4$ or $\operatorname{Tr} p v 4$, arguing against global downregulation of transcription in $\mathrm{KO}$ retinas. These findings suggest that TRPV4 and AQP4 activation not only modulate fluxes of cations and water but also influence the transcriptional regulation of osmoregulation-relevant genes in the retina. 

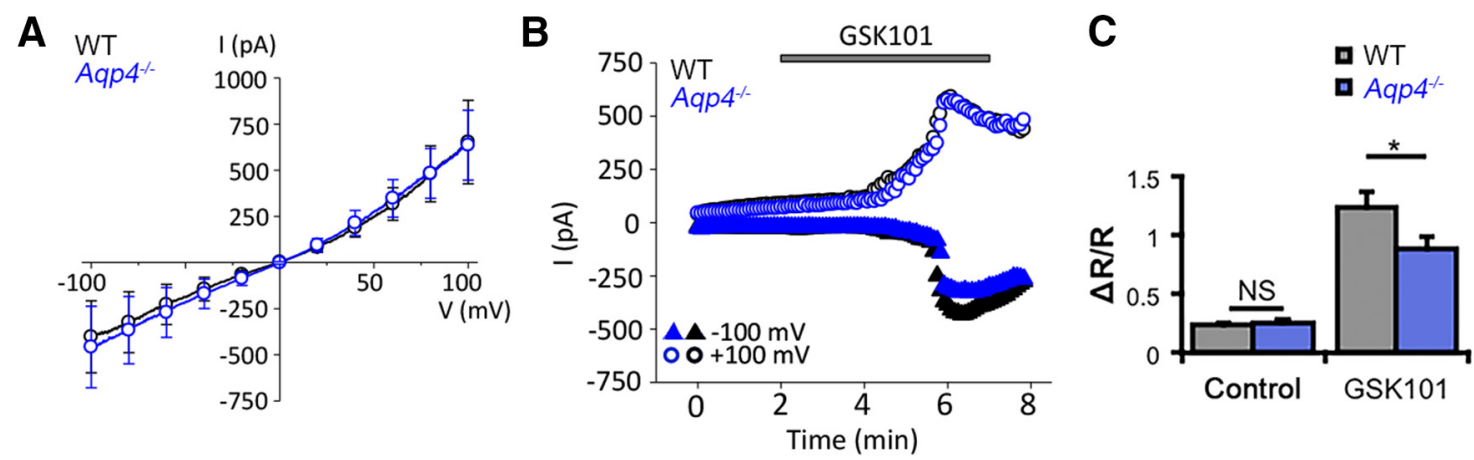

Figure 3. AQP4 is not required for agonist-induced TRPV4 activation. $A$, Averaged $I-V$ curves of GSK101-induced currents in WT (black trace) and Aqp4 ${ }^{-/-}$(blue trace) Müller cells. $B$,

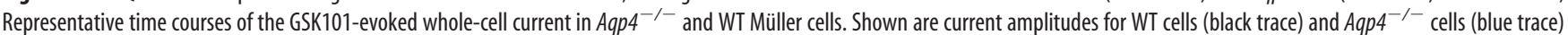
obtained at $100 \mathrm{mV}$ (circles) and $-100 \mathrm{mV}$ (triangles). C, The TRPV4 agonist GSK101 evokes a 5.3-fold increase in the fura-5F ratio in WT Müller cells over baseline activity ( $n=12$; gray bars). GSK101 responses were 3.4-fold larger than baseline activity in Aqp $4^{-/-}$Müller cells $(n=44$; blue bars) but significantly diminished compared with responses in WT cells. Shown are mean \pm SEM values.

\section{AQP4 is not required for TRPV4 activation}

Given TRPV4-AQP4 colocalization and the proposed obligatory interaction in cortical astrocytes (Benfenati et al., 2011), we investigated whether AQP4 is required for agonist-induced glial TRPV4 activation in mouse Müller glia. Müller cells were voltage clamped and stimulated with GSK101, a selective TRPV4 agonist at an approximate $\mathrm{EC}_{50}$ for Müller glia ( $\sim 25 \mathrm{~nm}$; Ryskamp et al., 2014). Voltage ramps over time revealed that GSK101 stimulated cation currents with slight outward rectification typical of TRPV4 (Fig. 3A). A representative time course of the whole-cell currents in an $A q p 4^{-1-}$ Müller cell is shown in Figure 3B. The cell exhibited the typical delayed activation of the TRPV4-mediated current, with a gradual increase-to-peak over several minutes of both inward and outward components (Fig. $3 B$ ) that reversed close to $0 \mathrm{mV}$ (Fig. 3A). GSK101-evoked responses were completely blocked by the selective antagonist HC-06 (Ryskamp et al., 2014). The response amplitudes and $I-V$ characteristics of GSK101-evoked currents in WT $(n=6)$ and Aqp4 $4^{-1-}$ Müller $(n=5)$ glia revealed no significant differences $(-402 \pm 195$ vs $-458 \pm 220 \mathrm{pA}$ at $-100 \mathrm{mV}$ and $652 \pm 226 \mathrm{vs} 636 \pm 189 \mathrm{pA}$ at $100 \mathrm{mV}$, respectively). AQP4 channels have been shown previously to influence TRPV4-dependent $\mathrm{Ca}^{2+}$ signals after swellinginduced stretch of the glial plasma membrane (Benfenati et al., 2011; Ryskamp et al., 2014). Therefore, we tested whether AQP4 was required for TRPV4-influenced $\mathrm{Ca}^{2+}$ homeostasis. The average spontaneous activity in $A q p 4^{-/-}$Müller glia at baseline, measured by the $340 / 380$ ratio of fura-5F fluorescence, was $0.26 \pm 0.03(n=44)$, not significantly different from WT cells $(n=12 ; p=0.8705$, Holm-Sidak test), suggesting that AQP4 channels do not contribute to the resting Müller cell $\left[\mathrm{Ca}^{2+}\right]_{i}$. To assess the activation properties of TRPV4 channels, we stimulated the cells with GSK101. [ $\left.\mathrm{Ca}^{2+}\right]_{\mathrm{i}}$ levels in $A q p 4^{-/-}$cells maintain the sensitivity to GSK101 stimulation, as indicated by the $88.9 \pm 10.3 \%(n=44)$ increase in the fluorescence ratio over the basal levels in the presence of the agonist (Fig. 3C). Nonetheless, comparison with signals in WT cells (124.4 $\pm 13.4 \%$ over baseline) revealed a modest $(\sim 28.6 \%)$ but significant $(p=0.0453$, Holm-Sidak test) decrease in GSK101-induced Aqp $4^{-/-}\left[\mathrm{Ca}^{2+}\right]_{\mathrm{i}}$ compared with WT. These data suggest the following: (1) AQP4 is not required for basal regulation of Müller cell $\left[\mathrm{Ca}^{2+}\right]_{\mathrm{i}}$ levels; (2) AQP4 modulates, but is not obligatory for, agonist-induced TRPV4 activation in Müller cells; and (3) decreased Trpv4 transcription in Aqp $4^{-1-}$ cells might be associated with functional decreases in the cellular response to swelling-evoked membrane stretch. The unaltered $I-V$ relationship and amplitude of the
GSK-induced TRPV4-mediated transmembrane current (Fig. $3 B$ ) suggest that loss of $A q p 4$ might predominantly affect secondary components of TRPV4-dependent $\mathrm{Ca}^{2+}$ homeostasis, such as ATP release, release from internal stores, and/or activation of store-operated channels.

\section{TRPV4 and AQP4 regulate hypotonic Müller glial swelling and RVD}

To test for functional interactions between TRPV4 and AQP4, we compared the magnitude and dynamics of volume changes during HTS in WT, Trpv $4^{-/-}$, and Aqp $4^{-/-}$Müller cells. Water influx across the plasma membrane was measured indirectly by tracking the changes in cell area and/or volume. Cell area was determined by outlining the perikaryal perimeter, whereas changes in glial volume were determined by the algebraic summation 340 and $380 \mathrm{~nm}$ emission fluorescence of fura-5F, yielding a $\mathrm{Ca}^{2+}$-independent signal inversely proportional to the cell volume (see Materials and Methods; Fig. 4A). HTS evoked sustained, dose-dependent and reversible increases in crosssectional area and volume in cells from all three genotypes, whereas hypertonic stimuli resulted in cell shrinkage (Fig. 4B). The initial response of Müller cells to osmotic challenge tracked the stressor magnitude, suggestive of the "osmometer-like" properties reported for cortical astrocytes (Risher et al., 2009). Anisotonicity-induced responses were reversible, with cell volume typically returning to baseline levels after $1-5 \mathrm{~min}$ in control saline (Fig. 4A,C). Trpv $4^{-/-}$cells showed significant decreases in peak swelling during HTS, whereas the maximal swelling in Aqp $4^{-/-}$cells was similar to controls (Fig. 4B). A $160 \mathrm{mOsm}$ tonicity decrease (46.7\% tonicity) enlarged the mean Müller cell area in $\operatorname{Tr} p v 4^{-/-}$cells by $19.84 \pm 1.23 \%(n=28)$, significantly less compared with $39.47 \pm 0.73 \%(n=33)$ in control cells $(p<$ 0.0001 , Dunnett's test), whereas the mean area of $A q p 4^{-/-}$cells increased by $37.59 \pm 0.52 \%(n=69 ; p=0.104$; Fig. $4 B)$. The reduction in the extent of Müller cell swelling by genetic elimination of the cation channel is consistent with the previously reported effects induced by pharmacological blockade of the channel (Ryskamp et al., 2014).

We next evaluated the time dependence of RVD in the response to sustained hypotonic stress. As illustrated in Figure 4, in WT cells, sustained exposure to large decreases in extracellular tonicity evokes slow but consistent decreases in cross-sectional area or volume relative to peak swelling, consistent with RVD. After reaching peak swelling, cell volume in HTS (140 mOsm)stimulated cells gradually declined toward the original volume 


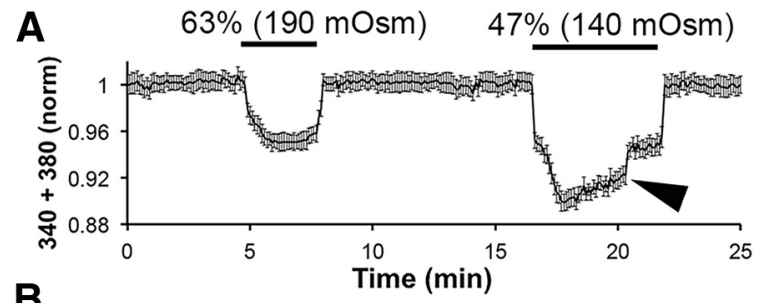

B

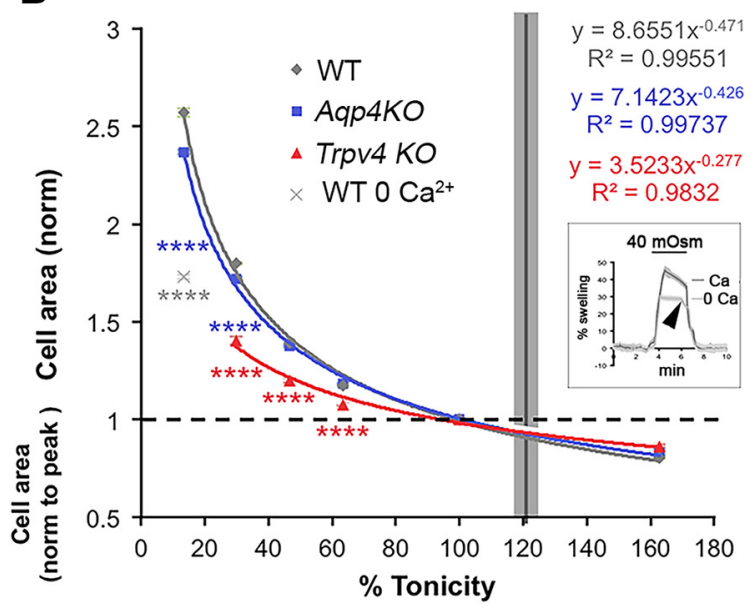

C

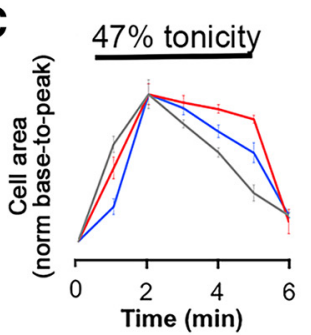

\section{D}
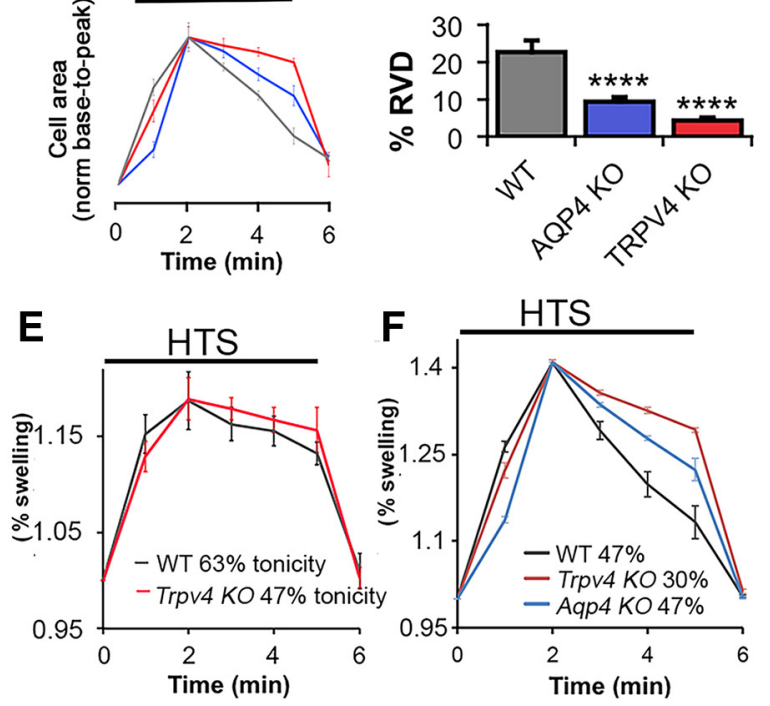

Figure 4. TRPV4-induced $\mathrm{Ca}^{2+}$ entry regulates Müller glial swelling and RVD. A, Cell volume changes in a fura-5F-loaded Müller cell. The sum of 340/380 emissions, adjusted to yield calcium-insensitive intensity values, shows dose-dependent decreases as cell volume increases in the presence of HTS. RVD is observed during the $140 \mathrm{~m} 0 \mathrm{sm}$ (46.67\% tonicity) but not 190 m0sm (63.33\% tonicity) stimulus (arrowhead). B, Dose-response curves for changes in peak perikaryal cross-sectional area in the presence of osmotic challenge show reduced glial swelling in $\operatorname{Trpv}^{-1-}$ ( $n=25-31$ cells per stimulus) but not substantially in Aqp4 ${ }^{-\prime-}$ cells $(n=$ 31-71) compared with WT cells $(n=27-61)$. Removal of extracellular $\mathrm{Ca}^{2+}$ during swelling of WT cells (13.3\% tonicity) shifted swelling to the extrapolated Trpv4 ${ }^{-/-}$curve (light gray data point; $n=27)$. Inset, Volume measurement ( $340+380$ signals, normalized to baseline) in WT cells $(n=8)$ exposed to extreme HTS ( $40 \mathrm{~m} 0 \mathrm{sm})$ and shown with inverted traces. Note the lower fluorescence decrease in $\mathrm{Ca}^{2+}$-free saline and the absence of RVD under these conditions (arrow).C, The time course of swelling in WT, Trpv4 ${ }^{-/-}$, and Aqp $4^{-/-}$cells during a 5 min exposure to $140 \mathrm{~m} 0$ sm HTS, normalized to base and peak cross-sectional areas to compare swelling kinetics. $\boldsymbol{D}$, RVD during exposure to $140 \mathrm{~m} 0$ sm HTS is impaired in Trpv4 ${ }^{-1-}(n=38)$ and Aqp4 $4^{-1-}(n=57)$ cells compared with WT cells $(n=52)$. E, WT and Trpv $4^{-1-}$ cell area over timenormalized to baseline (20\% peak swelling; $190 \mathrm{m0sm}$ for WT, $n=9 ; 140 \mathrm{m0sm}$ for Trpv4 ${ }^{-1-}$ cells, $n=8$ ). $\boldsymbol{F}$, WT, $\mathrm{Trpv}^{-1-}$, and $\mathrm{Aqp}^{-1-}$ cell area over time normalized to baseline (40\% peak swelling; $140 \mathrm{~m} 0 \mathrm{sm}$ for WT, $n=10 ; 90 \mathrm{m0sm}$ for Trpv4 ${ }^{-/-}$cells, $n=10 ; 140 \mathrm{~m} 0$ sm for Aqp $4^{-/-}$cells, $n=5$ ). (to $22.6 \pm 3.1 \%$ within a 5 min timeframe in WT Müller cells; $n=$ 52 ). Traces of cell area over time were overlaid by normalization to baseline and peak volume to compare the time course of swelling and RVD at $47 \%$ tonicity (Fig. $4 C$ ). This analysis indicated that, relative to WT Müller cells, swelling is delayed in Aqp4 $4^{-/-}$ Müller cells and that RVD is impaired in Aqp4 $4^{-/-}$cells $(n=57)$ and $\operatorname{Tr} p v 4^{-/-}$Müller cells $(n=38$ cells; $p<0.0001$ for both, Dunnett's test; Fig. $4 C, D, F)$. Because the peak HTS-induced swelling was reduced for the $\operatorname{Tr} p v 4^{-/-}$cells (Fig. $4 B$ ), a reduction in RVD in these cells compared with WT may be observed as a consequence of the different level of membrane stretch from which RVD is initiated. To examine the extent of RVD evoked from a similar amount of swelling, WT and $\operatorname{Trp} v 4^{-1-}$ Müller cells were exposed to sustained HTS of different magnitudes to obtain a similar level of swelling $\sim 15-20 \%$ (Fig. $4 E$ ) and $\sim 40 \%$ (Fig. $4 F)$. Under these comparable conditions, these genotypes responded similarly to the milder HTS stimulus (Fig. 4E). However, at $40 \%$ swelling, RVD was impaired in $\operatorname{Trp} v 4^{-/-}$and $A q p 4^{-/-}$Müller cells, suggesting that suppression of TRPV4 activation in these conditions (see below) may reduce RVD by inhibiting ion fluxes associated with triggering and enacting RVD (Fig. 4F). These data suggest the following: (1) TRPV4 activation contributes to HTS-induced glial swelling; (2) AQP4 accelerates swelling; (3) the degree of RVD depends on swelling amplitude; and (4) TRPV4 and AQP4 contribute to RVD for adaptation to extreme, nonphysiological hypotonic challenges.

\section{TRPV4 activation increases swelling in WT and $A q p 4^{-/-}$ Müller glia}

Given that the extent of HTS-induced swelling was reduced in Trp $v 4^{-/-}$Müller cells (Fig. $4 B$ ) and that GSK101- and HTSinduced $\mathrm{Ca}^{2+}$ elevations are abolished by the removal of external $\mathrm{Ca}^{2+}$ (Ryskamp et al., 2014), we tested whether TRPV4dependent changes in Müller cell area/volume require $\mathrm{Ca}^{2+}$ influx. Removal of extracellular $\mathrm{Ca}^{2+}$ reduced the HTS-induced cell swelling as determined by cell area (Fig. 4B) or volume (Fig. $4 B$, inset), suggesting that HTS-dependent swelling is promoted by TRPV4-mediated $\mathrm{Ca}^{2+}$ entry.

An alternative method for determining changes in cell volume is by using calcein, a fluorescein derivative that is independent of changes in intracellular ion concentrations (Crowe et al., 1995) and signals proportional changes in the volume of retinal neurons and glia (Ryskamp et al., 2011, 2014). Previously, we used calcein to show that HC-06 suppressed swelling in HTSstimulated WT Müller glia (Ryskamp et al., 2014). Analysis of $A q p 4^{-/-}$Müller glia revealed that the antagonist similarly suppresses the increase in cell volume in KO cells (Fig. 5A,B). Measurements of cell area likewise revealed a similar extent of peak glial swelling induced by 190 mOsm HTS (measured at 5 min after onset) between WT cells $(n=24)$ and Aqp $4^{-/-}$cells $(n=23$; Figs. $4 B, 5 C)$. The HTS-evoked increase in the cell area of Aqp $4^{-/-}$Müller cells $(n=12)$ continued to be suppressed by HC-06 ( $p<0.05$; Fig. $5 C)$, indicating that TRPV4 activation contributes to Müller cell swelling even in the absence of AQP4. WT, Trpv $4^{-/-}$, and Aqp $4^{-/-}$cells showed similar responses to the hypertonic stimulus (data not shown), suggesting that TRPV4 is not required for regulating the extent of osmotically induced volume decreases in Müller glia.

Together, these experiments suggest that TRPV4 channels regulate peak glial swelling by increasing $\left[\mathrm{Ca}^{2+}\right]_{\mathrm{i}}$, in a manner independent of the presence of AQP4. AQP4 functions as a passive conduit for osmotic water fluxes and increases, i.e., the rate of HTS-induced cell swelling while not being implicated in setting 

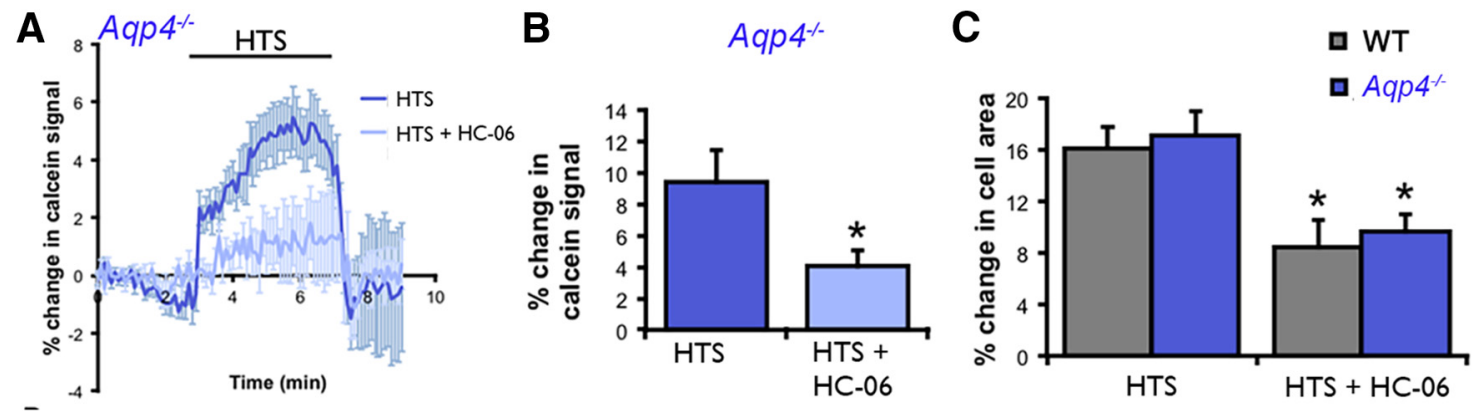

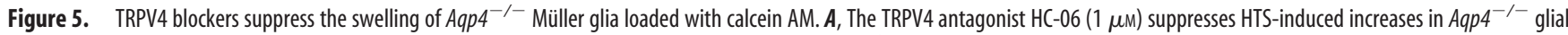
volume ( $190 \mathrm{~m} 0 \mathrm{sm} ; n=9$ cells from 5 slides). $B$, Cumulative data for cell volume measurements in Aqp4 ${ }^{-1-}$ cells stimulated with $190 \mathrm{~m} 0 \mathrm{sm}$ in the presence/absence of HC-06 ( $n=13$ and 20 , respectively).C,Cell area measurements revealed a similar extent of swelling after 5 min of HTS (190 m0sm) perfusion in WT ( $n=24)$ and Aqp $4^{-1-}(n=23)$ Müller cells. HC-06 (1 $\left.\mu \mathrm{m}\right)$ significantly decreased the extent of HTS-induced glial swelling in WT $(n=10)$ and Aqp4 ${ }^{-1-}(n=12)$ Müller cells.
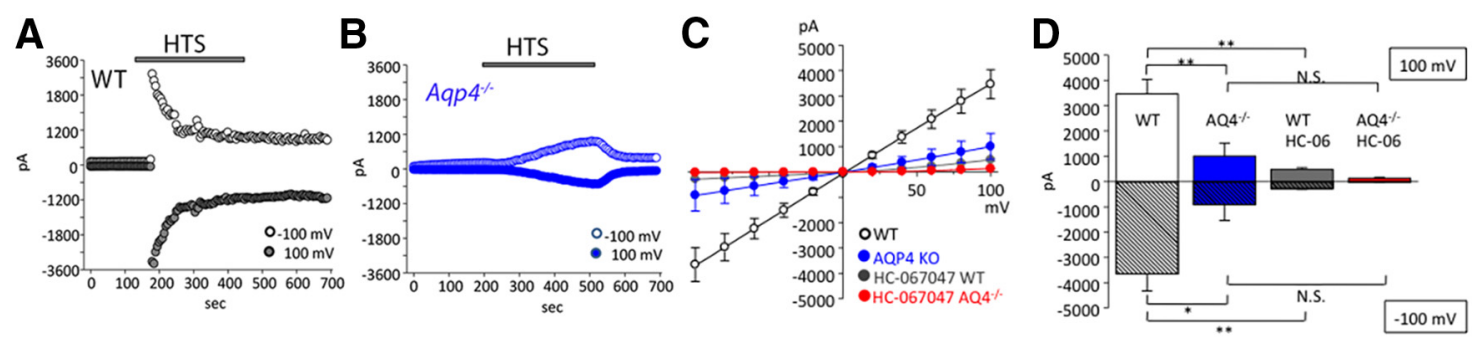

Figure 6. AQP4 regulates the amplitude and kinetics of the swelling-induced TRPV4-mediated transmembrane current. $A, B$, Representative time course of the HTS (235 m0sm)-evoked

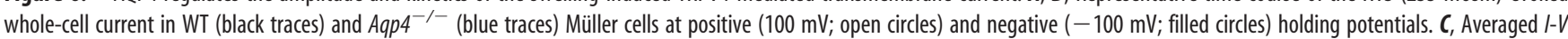
relationship of HTS-induced currents in WT (white; $n=14$ ) and Aqp ${ }^{-/-}$(blue; $n=13$ ) Müller cells, WT cells treated with HC-06 (gray; $n=5$ ), and Aqp $4^{-/-}$cells treated with HC-06 (red; $n=8$ ). Individual I-V curves of HTS-induced currents were subtracted from pre-HTS baselines. HC-06 was applied 4 min before the application of HTS and was present throughout the experiment. D, Summary for HTS-induced currents at $100 \mathrm{mV}$ (open bars) and $-100 \mathrm{mV}$ (shadowed bars) for WT (white) and Aqp $4^{-/-}$(blue) Müller cells, WT cells treated with HC-06 (gray), and Aqp $4^{-/-}$cells treated with HC-06.

the end volume after an osmotic challenge. Thus, TRPV4dependent $\mathrm{Ca}^{2+}$ signals might reorganize the mechanical properties of Müller glia, wherein the final volume is determined by a shift in the balance of tensile forces (e.g., from cytoskeletal elements) that counteract swelling and osmotic pressure forces that drive cell swelling.

\section{AQP4 channels amplify HTS-induced TRPV4-mediated currents and $\mathrm{Ca}^{2+}$ responses in Müller cells}

Exposure of HTS (190 mOsm) induced inward and outward currents in Müller end feet, which reached $-3982 \pm 751$ and $3703 \pm$ $635 \mathrm{pA}$ at holding potentials of -100 and $+100 \mathrm{mV}$, respectively $(n=8$; Fig. $6 A, D)$. Consistent with the strong immunoreactivity for TRPV4 (Fig. 1), the current amplitude was $\sim 10$-fold larger compared with signals measured previously in cell somata (Ryskamp et al., 2014). The full block of the HTS-evoked end foot current by HC-06 (Fig. 6C,D) indicates that it was primarily mediated by TRPV4. In addition to the larger response amplitude compared with the agonist-evoked response (Fig. 3), the $I-V$ relationship of the HTS-evoked current was more linear at positive potentials (Fig. $6 \mathrm{C}$ ), and the response was characterized by faster time-to-peak and desensitization of inward and outward components (Fig. 6A). Consistent with the slower rate of swellinginduced membrane stretch resulting from decreased water permeability, together with lower Trpv4 expression, $A q p 4^{-1-}$ cells showed a reduction in HTS-induced current amplitude to $-917 \pm 628$ and $1001 \pm 515 \mathrm{pA}$ at -100 and $100 \mathrm{mV}$, respectively $(n=8$ cells, $p<0.01$; Fig. $6 B-D)$. Aqp $4^{-/-}$cells also displayed slower activation; the swelling-evoked current reached its maximum at $202.5 \pm 32.2 \mathrm{~s}$ in $A q p 4^{-/-}$compared with $61.3 \pm$
$22.4 \mathrm{~s}$ in WT cells $(p<0.01$; Fig. $6 A, B)$. The magnitude and inactivation features of the HTS-induced current in $A q p 4^{-1-}$ cells appeared to be qualitatively similar to agonist-induced currents (Fig. 3). As opposed to WT cells, inactivation was notably absent in $A q p 4^{-1-}$ glia, at least for the duration of our stimulus (300 s; Fig. 6B). The antagonist HC-06 inhibited the HTSinduced current in WT and KO cells (Fig. 6C,D); however, the transmembrane current in HC-06-treated Aqp $4^{-/-}$cells was not significantly different from the response of cells that were not exposed to the TRPV4 antagonist (Fig. 6C,D). These electrophysiological findings indicate that the presence of AQP4 dramatically influences the time course and magnitude of HTS-induced TRPV4-dependent currents in Müller glia.

HTS-induced $\left[\mathrm{Ca}^{2+}\right]_{\mathrm{i}}$ signals were likewise strongly suppressed in Trpv $4^{-1-}$ Müller glia (Fig. 7 A,C). The amplitude of HTS ( $140 \mathrm{mOsm}$ )-evoked $\mathrm{Ca}^{2+}$ responses was reduced by $\sim 54 \%$ in $A q p 4^{-/-}$cells $(\Delta R / R$ of $0.34 \pm 0.03, n=13)$ compared with WT Müller cells $(\Delta R / R$ of $0.74 \pm 0.05, n=20 ; p<0.0001$, two-way ANOVA, Holm-Sidak test) and completely abolished in the presence of HC-06 (Fig. 7B). Interestingly, in cells challenged with exceedingly severe HTS (70\% reduction in tonicity), $\mathrm{Ca}^{2+}$ elevations in Aqp4 $4^{-/-}$Müller glia were substantial $(p<0.0001$, Dunnett's test) yet moderately (if significantly) lower than in WT cells $(p<0.001$; Fig. $7 C)$. The reliance of swelling-induced, but not agonist-induced, TRPV4 signals on AQP4 at modest-to strong levels of hypotonic stress suggests that the water channel primarily regulates TRPV4 through the swelling response, whereas the disappearance of this effect with extreme hypotonic stimuli indicates that the increased driving force for swelling 

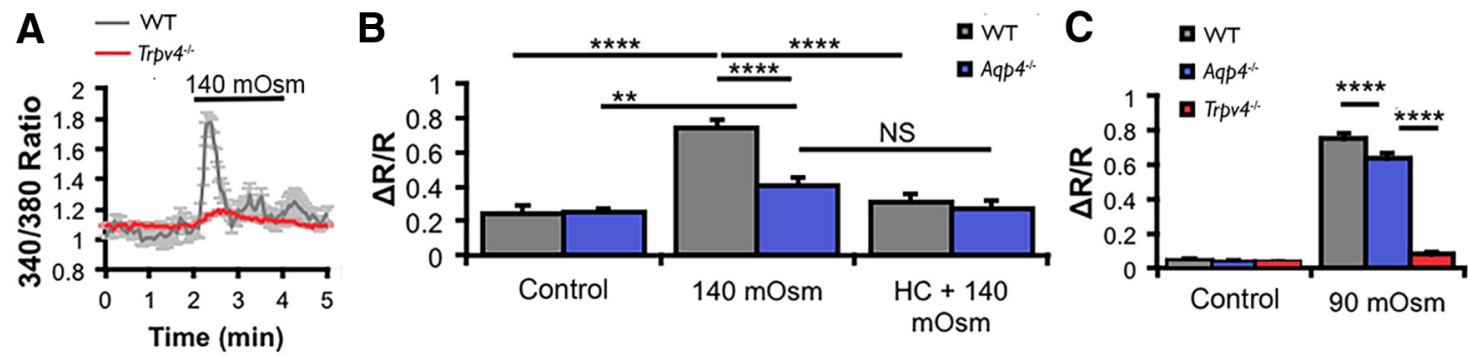

Figure 7. AQP4 amplifies glial HTS-induced TRPV4 activation with moderate $(140 \mathrm{~m} 0 \mathrm{sm})$ but not extreme $(90 \mathrm{~m} 0 \mathrm{sm}) \mathrm{HTS} . A, B, \mathrm{Ca}^{2+}$ signals in response to $140 \mathrm{~m} 0$ sm HTS were blocked in $\operatorname{Trpv}^{-1-}(n=50)$ and Aqp4 ${ }^{-1-}(n=64)$ Müller cells compared with WT cells $(n=20)$. HC-06 inhibited HTS-induced $\left[\mathrm{Ca}^{2+}\right]_{\mathrm{i}}$ elevations in WT cells $(n=14)$ but had no additional effect in Aqp4 $^{-1-}$ cells $(n=7)$, indicating that TRPV4 activation by HTS requires Aqp4. C, At excessively large hypotonic gradients ( $\left.90 \mathrm{~m} 0 \mathrm{sm}\right)$, Aqp $4^{-/-}$cells (blue bar) displayed robust HTS-induced $\left[\mathrm{Ca}^{2+}\right]_{\mathrm{i}}$ responses approaching those of the WT cells. Trpv $4^{-/-}$cells (red bar) showed no $\left[\mathrm{Ca}^{2+}\right]_{\mathrm{i}}$ response when challenged with HTS.

A

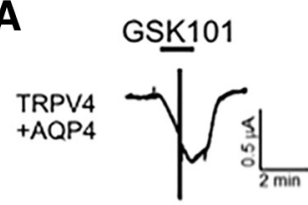

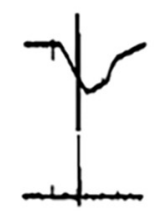

B Control
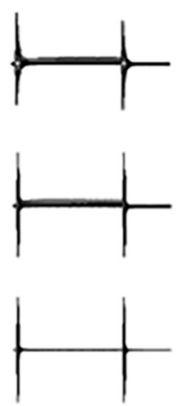

D
HTS
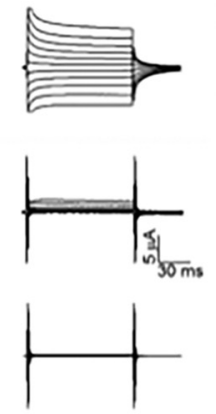

GSK101
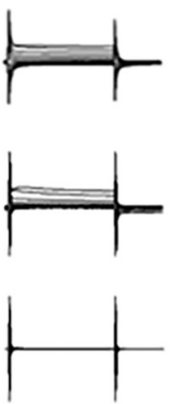

E
C

GSK101

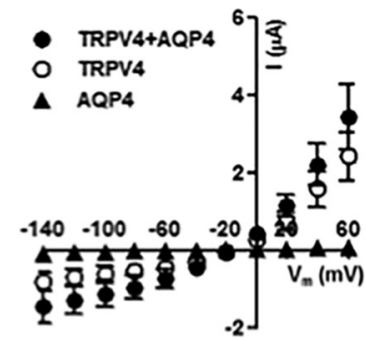

$\mathbf{F}$

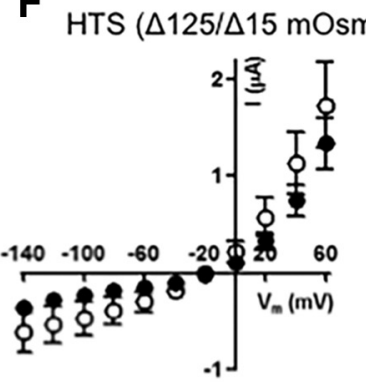

Figure 8. AQP4 channels amplify stretch-induced TRPV4 activation. $A, 0$, $\quad$ cytes expressing TRPV4 and AQP4 alone or in combination were voltage clamped at $V_{\mathrm{m}}=-30 \mathrm{mV}$ and exposed to 100 nм GSK101 (indicated by black bar). After $60 \mathrm{~s}$ GSK exposure, an I-V curve was obtained by jumping the clamp potential to potentials ranging from 60 to $-140 \mathrm{mV}$ at $20 \mathrm{mV}$ intervals (seen as the vertical lines in the current trace). $\boldsymbol{B}$, Representative I-V relations from oocytes expressing TRPV4 + AQP4, TRPV4, or AQP4 in control solution (left), in GSK101 solutions (right), or when exposed to $\Delta 125 \mathrm{~m}$ 0sm hypotonic challenge (middle). C, Summarized I-V relations obtained with GSK101 (as in $\boldsymbol{B} ; n=5-8$ ). $\boldsymbol{D}$, Representative current (black lines) and volume (gray lines) traces recorded simultaneously from oocytes expressing TRPV4 and AQP4 alone or in combination during exposure to a $\Delta 125 \mathrm{~m}$ 0sm hypotonic stimulus (indicated by the black bar; $n=5-9$ ). $E$, Summarized $/-V$ relations obtained during $\Delta 125 \mathrm{~m} 0 \mathrm{sm}$. $F$, 0ocytes expressing TRPV4 alone or in combination with AQP4 were exposed to hypotonic challenges of different magnitudes to observe similar degree of cell swelling ( $\Delta 125 \mathrm{~m}$ 0sm for TRPV4-expressing oocytes and $\Delta 15 \mathrm{~m} 0 \mathrm{sm}$ for TRPV4/AQP4-expressing 0ocytes), and I-V relations were obtained after $60 \mathrm{~s}$ of cell swelling $(n=8-9)$.

compensated for the loss of AQP4 or alternative swelling mechanisms contributed to TRPV4 activation independently of AQP4.

\section{AQP channels facilitate TRPV4 activation in the oocyte model system}

To further test whether AQP4 gates TRPV4 function through steric interactions or indirectly via swelling-induced membrane strain, the two channels were expressed, either alone or in combination, in the Xenopus oocyte expression system (Fig. 8). The cell volume and membrane currents were determined simultaneously after $60 \mathrm{~s}$ stimulation with HTS $(\Delta 125 \mathrm{mOsm})$ or GSK101. As expected, exposure to GSK101 induced inward currents in TRPV4-expressing oocytes (at $V_{\mathrm{m}}=60 \mathrm{mV} ; 2.4 \pm 0.6 \mu \mathrm{A}, n=7$ for TRPV4-expressing oocytes and $3.6 \pm 1.1 \mu \mathrm{A}, n=8$ for TRPV4/AQP4-expressing oocytes; Fig. 8A-C). The GSK101- induced currents were of similar magnitude whether AQP4 was coexpressed or not ( $p=0.9$, Student's $t$ test), whereas no current was observed in AQP4-expressing controls $(0.08 \pm 0.01 \mu \mathrm{A}, n=$ 5; Fig. $8 A-C$ ). Hypotonic cell swelling was more prominent in AQP4 expressors $(5.76 \pm 0.37 \%, n=5$ for AQP4-expressing oocytes, $4.25 \pm 0.24 \%, n=9$ for TRPV4/AQP4-expressing oocytes vs $0.33 \pm 0.04 \%, n=8$ in TRPV4-expressing oocytes, $p<$ 0.001, one-way ANOVA, with Dunnett's post hoc test; for representative volume traces, see Fig. $8 D$ ). The $I-V$ relationship measured $60 \mathrm{~s}$ after imposition of HTS yielded markedly larger currents in TRPV4/AQP4-expressing oocytes than oocytes expressing only TRPV4 (at $V_{\mathrm{m}}=60 \mathrm{mV} ; 6.3 \pm 1.5 \mu \mathrm{A}, n=9$ vs $1.7 \pm 0.4 \mu \mathrm{A}, n=8, p<0.05$, Student's $t$ test; Fig. $8 D, E)$. The increased HTS-induced current in oocytes coexpressing TRPV4 and $\mathrm{AQP} 4$ could be attributable to a required presence of $\mathrm{AQP} 4$ 
for full TRPV4 activity or to the increased AQP4-dependent oocyte swelling. Thus, we determined HTS-induced TRPV4mediated current in TRPV4-expressing oocytes and TRPV4/AQP4-expressing oocytes exposed to different osmotic gradients to obtain a similar degree of cell swelling $(\Delta 125 \mathrm{mOsm}$ for TRPV4expressing oocytes, $0.33 \pm 0.04 \%$ cell swelling after $60 \mathrm{~s}, n=8$ and $\Delta 15 \mathrm{mOsm}$ for TRPV4 + AQP4-expressing oocytes, $0.27 \pm 0.03 \%$ cell swelling after $60 \mathrm{~s}, n=$ $9 ; p=0.2$, Student's $t$ test). The $I$ - $V$ curves showed distinct overlap ( $p=0.4$, Student's $t$ test; Fig. $8 F$ ). Thus, AQP4 channels mediate activation of TRPV4 via their ability to facilitate cell swelling.

\section{Discussion}

Our results provide new insight into the molecular mechanisms that mediate the perception and transduction of osmotic stress in retinal Müller cells. The prominent colocalization of TRPV4 and AQP4 in perivascular Müller end feet suggests that the two channels are likely to play important functions in the exchange of water and ions across the blood-retina barrier. Consistent with this, functional analysis revealed a profound regulatory and functional interdependence between osmotically induced water transport and calcium signaling. Although data from $\mathrm{KO}$ mice indicate that TRPV4 and AQP4 are trafficked independently and are capable of autonomous activation, they also show that AQP4 augments swellinginduced activation of TRPV4 and that TRPV4 channels modulate water influx during a range of hypotonic challenges by increasing the membrane permeability to $\mathrm{Ca}^{2+}$. Additional evidence for the significance of TRPV4-AQP4 interactions in Müller glia was obtained in $\operatorname{Tr} p v 4^{-/-}$retinas, which exhibited marked reduction in the transcription of genes that include Aqp4 and Kir4.1, and in the oocyte expression system in which AQP4 expression facilitated the swelling-evoked activation of TRPV4 channels.

$\mathrm{Ca}^{2+}$ elevations in response to osmotic swelling have been observed across all biotic kingdoms, from plants (Johansson et al., 2000) and hagfish (Herr et al., 2014) to mammalian cells that include primary, cultured, and intact astrocytes (Kimelberg et al., 1992; Hoffmann et al., 2009). In vivo imaging studies showed that HTS-induced $\mathrm{Ca}^{2+}$ signals in astrocytes require Aqp4 (Thrane et al., 2011), whereas we found that TRPV4 is a main mediator of HTS-induced $\mathrm{Ca}^{2+}$ entry in Müller cells (Ryskamp et al., 2014). Here, we combine the insights from those studies to show that hypotonic challenges affect $\mathrm{Ca}^{2+}$ homeostasis and modulate glial cell volume via symbiotic interactions between the two channels. Functional AQP4 appears to be required for the maximal HTSinduced activation of TRPV4-mediated currents and $\left[\mathrm{Ca}^{2+}\right]_{\mathrm{i}}$ responses, whereas the vanilloid channel facilitates Müller cell volume increases and regulation in a $\mathrm{Ca}^{2+}$-dependent manner. Under our experimental conditions, Müller cells behaved in osmotic disequilibria as cellular osmometers, showing proportional swelling in hypotonic, and shrinking in hypertonic, solutions. These results are consistent with in vivo and in vitro data from the majority of cell types studied so far, including brain astrocytes (Pasantes-Morales et al., 2006; Risher et al., 2009), but differ from studies on rodent Müller glia that concluded that these cells resist hypotonic stress (Pannicke et al., 2004, Hirrlinger et al., 2008). The reasons for discrepant results are unclear but might involve different preparations, experimental means of detection of volume changes, and/or types of hypotonic stimuli (i.e., adding distilled water vis à vis mannitol supplementation; retinal slices vs dissociated cells). It is noteworthy that arachidonic acid, a proinflammatory $\omega 6$ polyunsaturated lipid, augments Müller cell sensitivity to hypotonic swelling (Reichenbach and Bringmann, 2010; Ryskamp et al., 2014), is required for activation of glial TRPV4 (Dunn et al., 2013), and also inhibits volume-regulated anion channels (VRACs) that mediate osmolyte release (Hoffmann et al., 2009). Therefore, as illustrated in Figure 9, loss of TRPV4-mediated signals in Aqp $4^{-/-}$Müller glia might have been influenced by reduced stimulation of $\mathrm{Ca}^{2+}$ activated isoforms of PLA2 (Lambert et al., 2006).

TRPV4-AQP4 interactions are particularly important for responses to hypotonic challenges, whereas WT, $\operatorname{Trp} v 4^{-1-}$, and Aqp $4^{-1-}$ cells showed similar decreases in cross-sectional area during exposure to hypertonic saline. Thus, the two channels together may contribute to regulation of glial swelling but not shrinkage. Removal of $\mathrm{Ca}^{2+}$ reproduced the effect of TRPV4 ablation by reducing the overall extent of HTS-induced swelling, suggesting that $\mathrm{Ca}^{2+}$ influx itself plays a key role in the initial volume increase. Decreased swelling in $\operatorname{Trpv} 4^{-/-}$cells might, in part, arise as a result of reduced expression of Aqp4 and Kir4.1 genes. We propose that the water channel modulates TRPV4 indirectly by facilitating swelling-induced stretch of the plasma membrane (Fig. 9). TRPV4 current amplitudes elicited at the $\mathrm{EC}_{50}$ for the agonist were an order of magnitude higher compared 
with currents elicited with a $40 \%$ reduction in tonicity, whereas the capacity of $A q p 4^{-1-}$ cells to respond to moderate swelling with increases in $\left[\mathrm{Ca}^{2+}\right]_{\mathrm{i}}$ was compromised even as the cells maintained responsiveness to GSK101. Notably, the facilitatory effect of AQP4 on the rate of HTS-induced glial swelling and the magnitude of cation influx was reproduced in TRPV4/AQP4expressing oocytes. Of particular interest is the observation that coexpression with AQP4 confers on TRPV4-expressing cells the capability to respond to considerably smaller osmotic gradients.

Our data expand the context of calcium involvement in volume regulation by showing an intriguing dual effect of TRPV4 activation consisting of positive (increased swelling) and negative (increased RVD) feedback loops. In contrast to cultured astrocytes, which show strong $(\sim 100 \%)$ RVD even in mild HTS (250 mOsm; Kimelberg et al., 1992; Benfenati et al., 2011), RVD in Müller glia and intact astrocytes is limited even in the presence of substantial hypotonic stress (Andrew and MacVicar, 1994; Risher et al., 2009; present study). Compared with WT cells, RVD was compromised in $\operatorname{Trpv4^{-1}}$ Müller glia during prolonged and substantial HTS. Thus, TRPV4 might contribute to adaptive volume regulation in retinal glia, as observed in airway epithelial, salivary gland, keratinocyte, and cortical glia and heterologously expressing CHO cells (Arniges et al., 2004; Becker et al., 2005; Liu et al., 2006; Benfenati et al., 2011). Under physiological conditions in which $\operatorname{Trpv4^{-/-}}$ cells swelled to a level comparable with that of the WT, the extent of volume regulation was comparable between the two genotypes. Given that RVD was observed mainly at hypotonic challenges that were out of the physiological range, we suggest that it may have limited physiological significance for Müller cell osmoregulation in vivo. The molecular mechanism underlying the net export of ions during RVD is unclear but could include activation of $\mathrm{Ca}^{2+}$ dependent channels, release of organic osmolytes, such as glutamate, taurine, and myo-inositol (Fischer et al., 1997; Hoffmann et al., 2009; Fernández et al., 2013), stimulation of VRACs that are sensitized by swelling-evoked $\mathrm{Ca}^{2+}$ microdomains (Akita and Okada, 2011), and/or activation of watertranslocating cotransporters (MacAulay and Zeuthen 2010).

Benfenati et al. (2011) proposed that TRPV4-dependent regulation of osmotic fluxes within the end foot requires an obligatory physical interaction with AQP4, whereas HTS-induced activation of TRPV4 in salivary gland epithelial cells appears to depend primarily on the interaction with AQP5 (Liu et al., 2006). Although we cannot exclude the possibility of direct association between the two proteins or their embedment within macromolecular entities involving Kir4.1, $\alpha$-syntrophin and/or dystrophins (Puwarawuttipanit et al., 2006; Lanciotti et al., 2012), our data suggest that the communication between the volume sensor and water influx can be explained adequately by indirect interaction mediated through transcription and cell swelling (Fig. 9). Thus, the amplitude of GSK101-mediated $\mathrm{Ca}^{2+}$ entry in Aqp $4^{-1-}$ cells mirrored signals in WT cells, whereas the cognate water channel AQP1 could substitute for AQP4 by facilitating swelling-induced activation of TRPV4 (N.M. and D.K., unpublished observations). This conjecture is supported by the functional independence of Kir4.1 from AQP4 (Ruiz-Ederra et al., 2007; Zhang and Verkman, 2008), despite the ability of AQP4 to facilitate hypotonic-induced activation of Kir4.1 (Soe et al., 2009). The precise mechanism responsible for the modest reduction in GSK101-induced $\left[\mathrm{Ca}^{2+}\right]_{\mathrm{i}}$ signals observed in Aqp $4^{-1-}$ cells remains to be determined but could involve reduced expression of Trpv4 (Fig. 2), release of ATP from cytosol or $\mathrm{Ca}^{2+}$ from internal stores (Lipp et al., 2009; Thrane et al., 2011).
Swelling of glial cells is a major cause of brain and retinal edema caused by liver disease, water intoxication, epilepsy, diabetes, stroke, and traumatic brain injury and can result in excitotoxicity, metabolic injury, and mechanical damage of blood vessels and neurons (Häussinger et al., 2000; Hirrlinger et al., 2008; Risher et al., 2009). Cysts, formed by swollen and dying Muller cells, are associated with macular edema that may drive ischemia and neuronal loss in diabetic retinopathy (Reichenbach and Bringmann, 2010). Edema formation, resulting from osmotic imbalances between retinal and extraretinal sites, is potentiated by fatty acids known to activate TRPV4 (Fig. 9), whereas deletion of AQP4 decreases the amplitude and frequency of $\mathrm{Ca}^{2+}$ signals during a hypotonic challenge and was associated with protection against the pathological effects of swelling, edema, and infarct (Manley et al., 2000; Da and Verkman, 2004; Thrane et al., 2011). Currently accepted interventions to treat brain swelling include cranial decompression and application of hyperosmolar hydrogels. We propose that cytotoxic $\mathrm{Ca}^{2+}$ signaling during glial swelling might instead be regulated by targeting TRPV4. The advantages of such interventions are the availability of specific antagonists (Vincent and Duncton, 2011) and the general absence of observable phenotypes in $\operatorname{Trpv4^{-/-}}$ mice (Everaerts et al., 2010). In the retina, additional benefit might be derived from neuroprotection conferred by inhibition of TRPV4 channels in RGCs (Križaj et al., 2014).

In conclusion, the synergistic mechanisms described here could represent a general cellular mechanism linking swellingdependent gene expression, $\mathrm{Ca}^{2+}$ homeostasis, and volume regulation in the brain. It is noteworthy that TRPV4/AQP4 channels are ideally positioned to sense and modulate ion/water fluxes across the blood-brain and blood-retina barrier, which is compromised during the formation of cytotoxic edema. TRPV4AQP4 interactions might also contribute to light-evoked ion fluxes and/or neuronal hyperexcitation within the retina (Huang and Karwoski, 1992; Dmitriev et al., 1999). Finally, our results point toward alternative strategies for mitigating the debilitating consequences of acute and chronic swelling in the retina and the brain.

\section{References}

Akita T, Okada Y (2011) Regulation of bradykinin-induced activation of volume-sensitive outwardly rectifying anion channels by $\mathrm{Ca}^{2+}$ nanodomains in mouse astrocytes. J Physiol 589:3909-3927. CrossRef Medline

Andrew RD, MacVicar BA (1994) Imaging cell volume changes and neuronal excitation in the hippocampal slice. Neuroscience 62:371-383. CrossRef Medline

Arniges M, Vázquez E, Fernández-Fernández JM, Valverde MA (2004) Swelling-activated $\mathrm{Ca}^{2+}$ entry via TRPV4 channel is defective in cystic fibrosis airway epithelia. J Biol Chem 279:54062-54068. CrossRef Medline

Becker D, Blase C, Bereiter-Hahn J, Jendrach M (2005) TRPV4 exhibits a functional role in cell-volume regulation. J Cell Sci 118:2435-2440. CrossRef Medline

Benfenati V, Caprini M, Dovizio M, Mylonakou MN, Ferroni S, Ottersen OP, Amiry-Moghaddam M (2011) An aquaporin-4/transient receptor potential vanilloid 4 (AQP4/TRPV4) complex is essential for cell-volume control in astrocytes. Proc Natl Acad Sci U S A 108:2563-2568. CrossRef Medline

Bringmann A, Skatchkov SN, Biedermann B, Faude F, Reichenbach A (1998) Alterations of potassium channel activity in retinal Müller glial cells induced by arachidonic acid. Neuroscience 86:1291-1306. CrossRef Medline

Chiavaroli C, Bird G, Putney JW Jr (1994) Delayed “all-or-none” activation of inositol 1, 4, 5-trisphosphate-dependent calcium signaling in single rat hepatocytes. J Biol Chem 269:25570-25575. Medline

Crowe WE, Altamirano J, Huerto L, Alvarez-Leefmans FJ (1995) Volume 
changes in single N1E-115 neuroblastoma cells measured with a fluorescent probe. Neuroscience 69:283-296. CrossRef Medline

Da T, Verkman AS (2004) Aquaporin-4 gene disruption in mice protects against impaired retinal function and cell death after ischemia. Invest Ophthalmol Vis Sci 45:4477-4483. CrossRef Medline

Dmitriev AV, Govardovskii VI, Schwahn HN, Steinberg RH (1999) Lightinduced changes of extracellular ions and volume in the isolated chick retina-pigment epithelium preparation. Vis Neurosci 16:1157-1167. CrossRef Medline

Dunn KM, Hill-Eubanks DC, Liedtke WB, Nelson MT (2013) TRPV4 channels stimulate $\mathrm{Ca}^{2+}$-induced $\mathrm{Ca}^{2+}$ release in astrocytic endfeet and amplify neurovascular coupling responses. Proc Natl Acad Sci U S A 110: 6157-6162. CrossRef Medline

Everaerts W, Zhen X, Ghosh D, Vriens J, Gevaert T, Gilbert JP, Hayward NJ, McNamara CR, Xue F, Moran MM, Strassmaier T, Uykal E, Owsianik G, Vennekens R, De Ridder D, Nilius B, Fanger CM, Voets T (2010) Inhibition of the cation channel TRPV4 improves bladder function in mice and rats with cyclophosphamide-induced cystitis. Proc Natl Acad Sci U S A 107:19084-19089. CrossRef Medline

Fenton RA, Moeller HB, Zelenina M, Snaebjornsson MT, Holen T, MacAulay N (2010) Differential water permeability and regulation of three aquaporin 4 isoforms. Cell Mol Life Sci 67:829-840. CrossRef Medline

Fernández JM, Di Giusto G, Kalstein M, Melamud L, Rivarola V, Ford P, Capurro C (2013) Cell volume regulation in cultured human retinal Müller cells is associated with changes in transmembrane potential. PLoS One 8:e57268. CrossRef Medline

Fischer R, Schliess F, Häussinger D (1997) Characterization of the hypoosmolarity-induced $\mathrm{Ca}^{2+}$ response in cultured rat astrocytes. Glia 20: 51-58. CrossRef Medline

Florence CM, Baillie LD, Mulligan SJ (2012) Dynamic volume changes in astrocytes are an intrinsic phenomenon mediated by bicarbonate ion flux. PLoS One 7:e51124. CrossRef Medline

Galizia L, Pizzoni A, Fernandez J, Rivarola V, Capurro C, Ford P (2012) Functional interaction between AQP2 and TRPV4 in renal cells. J Cell Biochem 113:580-589. CrossRef Medline

Goodyear MJ, Crewther SG, Junghans BM (2009) A role for aquaporin-4 in fluid regulation in the inner retina. Vis Neurosci 26:159-165. CrossRef Medline

Haj-Yasein NN, Bugge CE, Jensen V, Østby I, Ottersen OP, Hvalby Ø, Nagelhus EA (2015) Deletion of aquaporin-4 increases extracellular $\mathrm{K}^{+}$concentration during synaptic stimulation in mouse hippocampus. Brain Struct Funct 220:2469-2474. CrossRef Medline

Häussinger D, Kircheis G, Fischer R, Schliess F, vom Dahl S (2000) Hepatic encephalopathy in chronic liver disease: a clinical manifestation of astrocyte swelling and low-grade cerebral edema? J Hepatol 32:1035-1038. CrossRef Medline

Herr JE, Clifford AM, Goss GG, Fudge DS (2014) Defensive slime formation in Pacific hagfish requires $\mathrm{Ca}^{2+}$ - and aquaporin-mediated swelling of released mucin vesicles. J Exp Biol 217:2288-2296. CrossRef Medline

Hirrlinger PG, Wurm A, Hirrlinger J, Bringmann A, Reichenbach A (2008) Osmotic swelling characteristics of glial cells in the murine hippocampus, cerebellum, and retina in situ. J Neurochem 105:1405-1417. CrossRef Medline

Hoffmann EK, Lambert IH, Pedersen SF (2009) Physiology of cell volume regulation in vertebrates. Physiol Rev 89:193-277. CrossRef Medline

Huang B, Karwoski CJ (1992) Light-evoked expansion of subretinal space volume in the retina of the frog. J Neurosci 12:4243-4252. Medline

Huang W, Xing W, Ryskamp DA, Punzo C, Križaj D (2011) Localization and phenotype-specific expression of ryanodine calcium release channels in C57BL6 and DBA/2J mouse strains. Exp Eye Res 93:700-709. CrossRef Medline

Johansson I, Karlsson M, Johanson U, Larsson C, Kjellbom P (2000) The role of aquaporins in cellular and whole plant water balance. Biochim Biophys Acta 1465:324-342. CrossRef Medline

Kanemaru K, Kubota J, Sekiya H, Hirose K, Okubo Y, Iino M (2013) Calcium-dependent $\mathrm{N}$-cadherin up-regulation mediates reactive astrogliosis and neuroprotection after brain injury. Proc Natl Acad Sci U S A 110:11612-11617. CrossRef Medline

Kimelberg HK, Sankar P, O’Connor ER, Jalonen T, Goderie SK (1992) Functional consequences of astrocytic swelling. Prog Brain Res 94:57-68. CrossRef Medline

Križaj D, Copenhagen DR (1998) Compartmentalization of calcium extru- sion mechanisms in the outer and inner segments of photoreceptors. Neuron 21:249-256. CrossRef Medline

Križaj D, Ryskamp DA, Jo AO, Verkman A, MacAulay N (2013) Molecular coupling between TRPV4 and aquaporin 4 mediates osmosensation in Müller glial cells. Invest Ophthalmol Vis Sci 54:2673-2673.

Križaj D, Ryskamp DA, Tian N, Tezel G, Mitchell CH, Slepak VZ, Shestopalov VI (2014) From mechanosensitivity to inflammatory responses: new players in the pathology of glaucoma. Curr Eye Res 39:105-119. CrossRef Medline

Lambert IH, Pedersen SF, Poulsen KA (2006) Activation of PLA2 isoforms by cell swelling and ischaemia/hypoxia. Acta Physiologica 187:75-85. CrossRef Medline

Lanciotti A, Brignone MS, Molinari P, Visentin S, De Nuccio C, Macchia G, Aiello C, Bertini E, Aloisi F, Petrucci TC, Ambrosini E (2012) Megalencephalic leukoencephalopathy with subcortical cysts protein 1 functionally cooperates with the TRPV4 cation channel to activate the response of astrocytes to osmotic stress: dysregulation by pathological mutations. Hum Mol Genet 21:2166-2180. CrossRef Medline

Li J, Patil RV, Verkman AS (2002) Mildly abnormal retinal function in transgenic mice without Müller cell aquaporin-4 water channels. Invest Ophthalmol Vis Sci 43:573-579. Medline

Liedtke W, Friedman JM (2003) Abnormal osmotic regulation in trpv $4^{-/}$ mice. Proc Natl Acad Sci U S A 100:13698-13703. CrossRef Medline

Lipp S, Wurm A, Pannicke T, Wiedemann P, Reichenbach A, Chen J, Bringmann A (2009) Calcium responses mediated by type 2 IP 3-receptors are required for osmotic volume regulation of retinal glial cells in mice. Neurosci Lett 457:85-88. CrossRef Medline

Liu X, Bandyopadhyay B, Nakamoto T, Singh B, Liedtke W, Melvin JE, Ambudkar I (2006) A role for AQP5 in activation of TRPV4 by hypotonicity: concerted involvement of AQP5 and TRPV4 in regulation of cell volume J Biol Chem 281:15485-15495.

Loukin S, Zhou X, Su Z, Saimi Y, Kung C (2010) Wild-type and brachyolmia-causing mutant TRPV4 channels respond directly to stretch force. J Biol Chem 285:27176-27181. CrossRef Medline

Ma T, Yang B, Gillespie A, Carlson EJ, Epstein CJ, Verkman AS (1997) Generation and phenotype of a transgenic knockout mouse lacking the mercurial-insensitive water channel aquaporin-4. J Clin Invest 100:957962. CrossRef Medline

MacAulay N, Zeuthen T (2010) Water transport between CNS compartments: contributions of aquaporins and cotransporters. Neuroscience 168:941-956. CrossRef Medline

Manley GT, Fujimura M, Ma T, Noshita N, Filiz F, Bollen AW, Chan P, Verkman AS (2000) Aquaporin-4 deletion in mice reduces brain edema after acute water intoxication and ischemic stroke. Nat Med 6:159-163. CrossRef Medline

Minieri L, Pivonkova H, Harantova L, Anderova M, Ferroni S (2015) Intracellular $\mathrm{Na}^{+}$inhibits volume-regulated anion channel in rat cortical astrocytes. J Neurochem 132:286-300. CrossRef Medline

Molnar T, Barabas P, Birnbaumer L, Punzo C, Kefalov V, Križaj D (2012) Store-operated channels regulate intracellular calcium in mammalian rods. J Physiol 590:3465-3481. CrossRef Medline

Nagelhus EA, Ottersen OP (2013) Physiological roles of aquaporin-4 in brain. Physiol Rev 93:1543-1562. CrossRef Medline

Nagelhus EA, Veruki ML, Torp R, Haug FM, Laake JH, Nielsen S, Agre P, Ottersen OP (1998) Aquaporin-4 water channel protein in the rat retina and optic nerve: polarized expression in Müller cells and fibrous astrocytes. J Neurosci 18:2506-2519. Medline

Newman EA (1985) Membrane physiology of retinal glial (Muller) cells. J Neurosci 5:2225-2239. Medline

Pannicke T, Iandiev I, Uckermann O, Biedermann B, Kutzera F, Wiedemann P, Wolburg H, Reichenbach A, Bringmann A (2004) A potassium channel-linked mechanism of glial cell swelling in the postischemic retina. Mol Cell Neurosci 26:493-502. CrossRef Medline

Pannicke T, Wurm A, Iandiev I, Hollborn M, Linnertz R, Binder DK, Kohen L, Wiedemann P, Steinhäuser C, Reichenbach A, Bringmann A (2010) Deletion of aquaporin- 4 renders retinal glial cells more susceptible to osmotic stress. J Neurosci Res 88:2877-2888. CrossRef Medline

Papadopoulos MC, Verkman AS (2013) Aquaporin water channels in the nervous system. Nat Rev Neurosci 14:265-277. CrossRef Medline

Pasantes-Morales H, Lezama RA, Ramos-Mandujano G, Tuz KL (2006) Mechanisms of cell volume regulation in hypo-osmolality. Am J Med 119:S4-S11. CrossRef Medline 
Puwarawuttipanit W, Bragg AD, Frydenlund DS, Mylonakou MN, Nagelhus EA, Peters MF, Kotchabhakdi N, Adams ME, Froehner SC, Haug FM, Ottersen OP, Amiry-Moghaddam M (2006) Differential effect of $\alpha$-syntrophin knockout on aquaporin-4 and Kir4.1 expression in retinal macroglial cells in mice. Neuroscience 137:165-175. CrossRef Medline

Reichenbach A, Bringmann A (2010) Müller cells in the healthy and diseased retina. New York: Springer Science and Business Media.

Risher WC, Andrew RD, Kirov SA (2009) Real-time passive volume responses of astrocytes to acute osmotic and ischemic stress in cortical slices and in vivo revealed by two-photon microscopy. Glia 57:207-221. CrossRef Medline

Ruiz-Ederra J, Zhang H, Verkman AS (2007) Evidence against functional interaction between aquaporin-4 water channels and Kir4. 1 potassium channels in retinal Müller cells. J Biol Chem 282:21866-21872. CrossRef Medline

Ryskamp DA, Witkovsky P, Barabas P, Huang W, Koehler C, Akimov NP, Lee SH, Chauhan S, Xing W, Rentería RC, Liedtke W, Križaj D (2011) The polymodal ion channel transient receptor potential vanilloid 4 modulates calcium flux, spiking rate, and apoptosis of mouse retinal ganglion cells. J Neurosci 31:7089-7101. CrossRef Medline

Ryskamp DA, Jo AO, Frye AM, Vazquez-Chona F, MacAulay N, Thoreson WB, Križaj D (2014) Swelling and eicosanoid metabolites differentially gate TRPV4 channels in retinal neurons and glia. J Neurosci 34:1568915700. CrossRef Medline

Ryskamp DA, Iuso A, Križaj D (2015) TRPV4 links inflammatory signaling and neuroglial swelling. Channels 9:70-72. CrossRef Medline

Schliess F, Sinning R, Fischer R, Schmalenbach C, Häussinger D (1996) Calcium-dependent activation of Erk-1 and Erk-2 after hypo-osmotic astrocyte swelling. Biochem J 320:167-171. CrossRef Medline
Shibasaki K, Ikenaka K, Tamalu F, Tominaga M, Ishizaki Y (2014) A novel subtype of astrocytes expressing TRPV4 (transient receptor potential vanilloid 4) regulates neuronal excitability via release of gliotransmitters. J Biol Chem 289:14470-14480. CrossRef Medline

Soe R, Macaulay N, Klaerke DA (2009) Modulation of Kir4.1 and Kir4.1Kir5.1 channels by small changes in cell volume. Neurosci Lett 457: 80-84. CrossRef Medline

Szikra T, Barabas P, Bartoletti TM, Huang W, Akopian A, Thoreson WB, Križaj D (2009) Calcium homeostasis and cone signaling are regulated by interactions between calcium stores and plasma membrane ion channels. PLoS One 4:e6723. CrossRef Medline

Thrane AS, Rappold PM, Fujita T, Torres A, Bekar LK, Takano T, Peng W, Wang F, Rangroo Thrane V, Enger R, Skare $\varnothing$, Holen T, Klungland A, Ottersen OP, Nedergaard M, Nagelhus EA (2011) Critical role of aquaporin-4 (AQP4) in astrocytic $\mathrm{Ca}^{2+}$ signaling events elicited by cerebral edema. Proc Natl Acad Sci U S A 108:846-851. CrossRef Medline

Vincent F, Duncton MA (2011) TRPV4 agonists and antagonists. Curr Top Med Chem 11:2216-2226. CrossRef Medline

Witkovsky P, Gábriel R, Križaj D (2008) Anatomical and neurochemical characterization of dopaminergic interplexiform processes in mouse and rat retinas. J Comp Neurol 510:158-174. CrossRef Medline

Zeuthen T, Belhage B, Zeuthen E (2006) Water transport by $\mathrm{Na}^{+}$-coupled cotransporters of glucose (SGLT1) and of iodide (NIS). The dependence of substrate size studied at high resolution. J Physiol 570:485-499. CrossRef Medline

Zhang H, Verkman AS (2008) Aquaporin-4 independent Kir4. $1 \mathrm{~K}^{+}$channel function in brain glial cells. Mol Cell Neurosci 37:1-10. CrossRef Medline 